\title{
Oxidative desulfurization strategies using Keggin-type polyoxometalate catalysts: biphasic versus solvent-free systems
}

Susana O. Ribeiro, ${ }^{a}$ Carlos M. Granadeiro, ${ }^{\mathrm{a}, \mathrm{b}}$ Pedro L. Almeida, ${ }^{\mathrm{c}}$ João Pires, ${ }^{\mathrm{d}}$ Maria C. Capel-Sanchez, ${ }^{e}$ José M. Campos-Martin, ${ }^{\mathrm{e}}$ Baltazar de Castro ${ }^{\mathrm{a}}$ and Salete S. Balula ${ }^{\mathrm{a}^{*}}$

a REQUIMTE-LAQV, Departamento de Química e Bioquímica, Faculdade de Ciências, Universidade do Porto, 4169-007 Porto, Portugal

${ }^{b}$ Departamento de Química, CICECO-Instituto de Materiais de Aveiro, Universidade de Aveiro, Campus Universitário de Santiago, 3810-193 Aveiro, Portugal

${ }^{c}$ CENIMAT/I3N, Faculdade de Ciências e Tecnologia, Universidade Nova de Lisboa, 2829-516 Monte da Caparica, and AD Física, ISEL/IPL, R. Conselheiro Emídio Navarro, 1, 1959-007 Lisboa, Portugal

${ }^{d}$ Centro de Química e Bioquímica, Faculdade de Ciências, Universidade de Lisboa, 1749-016 Lisboa, Portugal

e Grupo de Energía y Química Sostenibles (EQS), Instituto de Catálisis y Petroleoquímica, CSIC, Marie Curie, 2 Canto Blanco, Madrid, Spain

\begin{abstract}
Strategic polyoxometalate Keggin-type structural modification was performed to increase the oxidative catalytic performance to desulfurize model and real diesels. The most active lacunar structure $\left[\mathrm{PW}_{11} \mathrm{O}_{39}\right]^{7-}\left(\mathrm{PW}_{11}\right)$ showed to complete desulfurize a simulated diesel after $60 \mathrm{~min}$ at $70{ }^{\circ} \mathrm{C}$. Its application as homogeneous catalyst using a biphasic system 1:1 diesel/acetonitrile needed to use an excess of oxidant (ratio $\mathrm{H}_{2} \mathrm{O}_{2} / \mathrm{S}=8$ ). The immobilization of the $\mathrm{PW}_{11}$ on an amine-functionalized SBA-15 originated a heterogeneous catalyst PW $11 @$ aptesSBA-15 with identical oxidative desulfurization performance as the homogeneous analogue. As advantage, the heterogeneous catalyst promotes the complete desulfurization of simulated diesel using a solvent-free system, i.e. without the need of acetonitrile use. On the other hand, the same desulfurization efficiency could be achieved using half amount of oxidant $\left(\mathrm{H}_{2} \mathrm{O}_{2} / \mathrm{S}=4\right)$. The oxidative desulfurization of the real diesel achieved a remarkable $83.4 \%$ of efficiency after just $2 \mathrm{~h}$. The recycle capacity of PW $\mathrm{PW}_{11} @$ aptesSBA-15 catalyst was confirmed for eight consecutive cycles using the biphasic and the solvent-free systems. Its stability investigation demonstrates to be higher under the solvent-free system than the biphasic system, without practically any occurrence of $\mathrm{PW}_{11}$ leaching in the first case. On the other hand, the Venturello
\end{abstract}


peroxocomplex $\left[\mathrm{PO}_{4}\left\{\mathrm{~W}\left(\mathrm{O}_{2}\right)_{2}\right\}_{4}\right]^{3-}$, recognized as active intermediated in the homogeneous biphasic system, was not identified in the heterogeneous catalytic systems.

Keywords: Oxidative desulfurization; Real diesel; Heterogeneous catalysis; Polyoxotungstates; Hydrogen peroxide.

\section{Introduction}

The production of environmental friendly fuels involves the removal of organic sulfur compounds, since these compounds are responsible for important environmental problems as acid rain, but also refinery catalyst fouling as well as corrosion of engines.[1, 2] Hydrodesulfurization (HDS) has been the conventional process found by refineries to deal with the removal of sulfur from fuels. However, large efforts need to be done to find an alternative process since HDS is an expensive method to produce ultra-low sulfur fuels, since this needs to operate at high temperature and high $\mathrm{H}_{2}$ pressure. Oxidative desulfurization (ODS) has been highlighted as a promising complementary or alternative method since high efficiency can be achieved under mild reaction conditions. The investigation of efficient catalytic systems capable to oxidize selectively sulfides to sulfones is of high importance since this is the main step of the process to produce low-sulfur fuels. Therefore, it is crucial to develop active, selective and robust catalytic systems that can be efficiently recycled and recovered from the desulfurization process.[2]

Polyoxometalates (POMs) are metal-oxygen anionic clusters that have been attracting much interest due to their unique properties in oxidative catalysis [3-5], with the Keggin-type $\left(\left[\mathrm{XM}_{12} \mathrm{O}_{40}\right]^{\mathrm{n}-}\right)$ POMs being the most investigated in this area of application. Most of the published work reports the phosphotungstic acid $\mathrm{H}_{3}\left[\mathrm{PW}_{12} \mathrm{O}_{40}\right] \cdot \mathrm{nH}_{2} \mathrm{O}$ as catalyst or catalyst precursor for various oxidative catalysis. [6-8] Important Keggin-type derivatives include the lacunar polyanions $\left(\left[\mathrm{XM}_{11} \mathrm{O}_{39}\right]^{(\mathrm{n}+4)-}\right)$ that results by the removal of one $\mathrm{MO}^{4+}$ unit. The lacunar POMs contain free oxygen atoms with coordinative capacity to incorporate different transition metals in their structure. In this case, mono-substituted POMs $\left(\left[\mathrm{XM}_{11} \mathrm{M}^{\prime}\left(\mathrm{H}_{2} \mathrm{O}\right) \mathrm{O}_{40}\right]^{\mathrm{p}-}\right)$ can be prepared by the coordination of $\mathrm{M}^{\prime}$ transition metal with five $\mathrm{O}^{2-}$ ligands from the lacuna. The application of transition-metal-substituted POMs as catalysts uses the advantage of open coordination sites on the transition metal by displacement of the water ligand. [7]

Several approaches have been made to prepare efficient heterogeneous POMs base catalysts for oxidative desulfurization of fuels. [9] Various strategies have been followed to 
incorporate active catalytic POMs in different materials, including metal organic frameworks, [10-12] silica matrixes [2, 13-18] and also by hybridization methodologies. [19, 20] Between these, silica materials have the advantage of high specific surface areas, thermal stability, lightweight and extending framework composition. Moreover, the surface of silica can be easily modified by reacting with organosilanes containing appropriate functional groups. Among the several mesoporous silica materials, SBA-15 has been successfully used as support material due to its high hydrothermal stability and large pore size. [21-25] Anchoring transition-metal-substituted POMs on the surface of amino-functionalized SBA-15 has proved to be highly efficient in minimizing leaching owing to the strong interaction between the POM and the amine-functionalized surface via dative bonding. $[7,26]$ Recently, our research group has given some attention to the zinc mono-substituted phosphotungstate $\left[\mathrm{PW}_{11} \mathrm{Zn}\left(\mathrm{H}_{2} \mathrm{O}\right) \mathrm{O}_{39}\right]^{5-}$, since it reveals good catalytic activity in oxidative desulfurization. [12, 13, 27]

This manuscript reports the application of different strategies adopted in the oxidative desulfurization process to remove efficiently the most refractory sulfur compounds from a model and a real diesel supplied by CEPSA. The oxidative desulfurization processes were catalyzed by various Keggin-type derivative POMs and a lacunary POM based solid catalyst using amine-functionalized SBA-15 as support. The hydrogen peroxide was the used oxidant. The sustainability of the process and the efficiency of the system were optimized. Total model diesel desulfurization was achieved under mild reaction after only $60 \mathrm{~min}$. The recyclability of the catalyst was investigated and its robustness was analyzed.

\section{Experimental section}

\subsection{Materials and methods}

All the reagents used in the polyoxometalates (POMs) synthesis, support and composite preparation, namely (3-aminopropyl)triethoxysilane (aptes, Aldrich), anhydrous toluene 99.8\% (Aldrich), ethanol (Aga), hydrochloric acid ( $\mathrm{HCl}$, Fisher Chemicals), pluronic P123 (Aldrich), phosphotungstic acid (Fluka), potassium chloride (Aldrich), sodium hydrogen phosphate dihydrate (Aldrich), sodium tungstate dihydrate (Aldrich), tetra-n-butylammonium bromide (TBA, Merck), tetraethoxysilane (TEOS, Aldrich) and zinc acetate dehydrate (M\&B) were used as received. The reagents for oxidative desulfurization reactions, including 1benzothiophene (1-BT, Fluka), dibenzothiophene (DBT, Aldrich), 4-methyldibenzothiophene (4MDBT, Aldrich), 4,6-dimethyldibenzothiophene (4,6-DMDBT Alfa Aesar), acetonitrile (MeCN, 
Fisher Chemical), hydrogen peroxide aq. 30\% (Aldrich) and $n$-octane (Aldrich) were purchased from chemical suppliers and used without further purification.

Elemental analyses for $\mathrm{C}, \mathrm{H}$ and $\mathrm{N}$ elements were performed in a Leco CHNS-932 instrument and $\mathrm{Si}, \mathrm{W}$ and $\mathrm{P}$ by ICP-OES on a Perkin-Elmer Optima 4300 DV instrument; at the University of Santiago de Compostela. FT-IR spectra were obtained on a Jasco 460 Plus spectrometer using $\mathrm{KBr}$ pellets, while the FT-Raman spectra were recorded on a RFS-100 Bruker FT-spectrometer equipped with a Nd:YAG laser with an excitation wavelength of $1064 \mathrm{~nm}$ and the laser power set to $350 \mathrm{~mW}$. Powder X-ray diffraction (XRD) patterns were obtained at room temperature on a X'Pert MPD Philips diffractometer, equipped with a $X^{\prime}$ Celerator detector and a flat-plate sample holder in a Bragg-Brentano para-focusing optics configuration ( $45 \mathrm{kV}, 40 \mathrm{~mA}$ ). Intensity data were collected by the step-counting method (step $0.013^{\circ}$ ), in continuous mode, in the ca. $0.3 \leq 2 \theta \leq 10^{\circ}$ range. ${ }^{31} \mathrm{P}$ NMR spectra were collected for liquid solutions using a Bruker Avance III 400 spectrometer and chemical shifts are given with respect to external $85 \% \mathrm{H}_{3} \mathrm{PO}_{4}$. Solid state ${ }^{13} \mathrm{C},{ }^{31} \mathrm{P}$ and ${ }^{29} \mathrm{Si} \mathrm{MAS} N \mathrm{NMR}$ spectra were acquired with a Bruker AVANCE III 300 spectrometer (7 T) operating respectively at $75 \mathrm{MHz}$ $\left({ }^{13} \mathrm{C}\right), 121 \mathrm{MHz}\left({ }^{31} \mathrm{P}\right)$ and $60 \mathrm{MHz}\left({ }^{29} \mathrm{Si}\right)$, equipped with a BBO probe head. The samples were spun at the magic angle at a frequency of $5 \mathrm{kHz}$ in $4 \mathrm{~mm}$-diameter rotors at room temperature. The ${ }^{13} \mathrm{C}$ MAS NMR experiments were acquired with proton cross polarization (CP MAS) with a contact time of $1.2 \mathrm{~ms}$, and the recycle delay was $2.0 \mathrm{~s}$. The ${ }^{29} \mathrm{Si}$ MAS NMR spectra were obtained by a single pulse sequence with a $90^{\circ}$ pulse of $4.5 \mu \mathrm{s}$ at a power of $40 \mathrm{~W}$, and a relaxation delay of $10.0 \mathrm{~s}$. The ${ }^{29} \mathrm{Si}$ CP MAS NMR experiments were acquired with a contact time of $1.2 \mathrm{~ms}$, and the recycle delay was $5.0 \mathrm{~s}$. The ${ }^{31} \mathrm{P}$ MAS NMR spectra were obtained by a single pulse sequence with a $90^{\circ}$ pulse of $5.0 \mu$ s at a power of $20 \mathrm{~W}$, and a relaxation delay of $2.0 \mathrm{~s}$. Scanning electron microscopy (SEM) and energy dispersive X-ray spectroscopy (EDS) studies were performed at "Centro de Materiais da Universidade do Porto" (CEMUP, Porto, Portugal) using a high-resolution (Schottky) scanning electron microscope with $\mathrm{X}$-ray microanalysis and electron backscattered diffraction analysis Quanta 400 FEG ESEM/EDAX Genesis X4 M. The samples were studied as powders and were coated with an Au/Pd thin film by sputtering using the SPI Module Sputter Coater equipment. The textural characterization was obtained from physical adsorption of nitrogen at $-196{ }^{\circ} \mathrm{C}$, using a Quantachrome NOVA 2200 e instrument. Samples were degassed at $120^{\circ} \mathrm{C}$ for at least $5 \mathrm{~h}$ prior to the measurements. The BET surface area $\left(A_{B E T}\right)$ was calculated by using the relative pressure data in the 0.05-0.3 range. The total pore volume $(\mathrm{Vp})$ was evaluated on the basis of the amount adsorbed at a relative pressure of about 0.95. GC-FID was carried out in a Varian CP-3380 
chromatograph to monitor the ODS multicomponent model oil experiments. Hydrogen was used as the carrier gas ( $55 \mathrm{~cm} \mathrm{~s}-1)$ and fused silica Supelco capillary columns SPB-5 (30 m x $0.25 \mathrm{~mm}$ i.d.; $25 \mu \mathrm{m}$ film thickness) were used. The sulfur content of untreated diesel was qualified by GC-FID/SCD in an Agilent $7890 \mathrm{~A}$ and quantified based in coulombiometric measurements in a TOX-100 S, at Instituto de Catálisis y Petroleoquímica, CSIC in Madrid (Spain).

\subsection{Synthesis and preparation of the materials}

\subsubsection{Synthesis of polyoxometalates}

The tetra- $n$-butylammonium (TBA, $\left.\left(\mathrm{C}_{4} \mathrm{H}_{9}\right)_{4} \mathrm{~N}\right)$ salt of Keggin type polyoxometalates were prepared: $\left.\left.\left[\mathrm{PW}_{11} \mathrm{Zn}\left(\mathrm{H}_{2} \mathrm{O}\right) \mathrm{O}_{39}\right)\right]^{5-}\left(\mathbf{P W}_{11} \mathrm{Zn}\right), \quad\left[\mathrm{PW}_{11} \mathrm{O}_{39}\right)\right]^{7-}\left(\mathrm{PW}_{11}\right)$ and $\left[\mathrm{PW}_{12} \mathrm{O}_{40}\right]^{3-}\left(\mathbf{P W}_{12}\right)$. The zinc mono-substituted phosphotungstate $\left(\mathrm{PW}_{11} \mathrm{Zn}\right)$ was prepared according to previously reported methods by our group. $[19,28]$ Briefly, $\mathrm{Na}_{2} \mathrm{HPO}_{4}(1.8 \mathrm{mmol})$ and $\mathrm{Na}_{2} \mathrm{WO}_{4} \cdot 2 \mathrm{H}_{2} \mathrm{O}(20 \mathrm{mmol})$ were dissolved in $40 \mathrm{ml}$ of water, the mixture was heated at $85^{\circ} \mathrm{C}$ for 1 hour and the $\mathrm{pH}$ was adjusted to 4.8 with $\mathrm{HCl} 4 \mathrm{M}$. Zinc acetate $(2.4 \mathrm{mmol})$ was then added and stirred until completely dissolved. An excess of TBA bromide was added and after cooling to room temperature, the former white precipitate was filtered and dried in a desiccator over silica gel. The lacunar $\mathrm{PW}_{11}$ was prepared similarly, except for the addition of zinc acetate. The TBA salt of the Keggin polyanion $\mathrm{PW}_{12}$ was prepared by simply dissolving the phosphotungstic acid in water and adding an excess of TBA bromide. [10] The successful preparation of the POMs was confirmed by FT-IR, and ${ }^{31} \mathrm{P}$ NMR spectroscopies.

PW 11 Zn: ${ }^{31} \mathrm{P}\left(161.9 \mathrm{MHz}, \quad \mathrm{D}_{2} \mathrm{O} 298 \mathrm{~K}\right): \delta=-10.65 \mathrm{ppm}$. Selected FT-IR $\left(\mathrm{cm}^{-1}\right): v=2952(\mathrm{w})$, $2938(w), 1622(\mathrm{~m}), 1088(\mathrm{~s}), 1050(\mathrm{~s}), 956(\mathrm{vs}), 886(\mathrm{~s}), 800$ (s), $754(\mathrm{~m}), 700(\mathrm{~m}), 590(\mathrm{w}), 506$ $(w), 484(w), 408(w)$.

$\mathrm{PW}_{11}:{ }^{31} \mathrm{P}\left(161.9 \mathrm{MHz}, \quad \mathrm{D}_{2} \mathrm{O} 298 \mathrm{~K}\right): \delta=-11.41 \mathrm{ppm}$. Selected FT-IR $\left(\mathrm{cm}^{-1}\right): \mathrm{v}=3445(\mathrm{~m}), 2359$ (w), 2343(sh), $1616(w), 1090(s), 1040(s), 953(s), 904(m), 852(w), 807(m), 761(s h), 728(m)$, $593(w), 511(m), 417(w)$

$\mathrm{PW}_{12}:{ }^{31} \mathrm{P}\left(161.9 \mathrm{MHz}, \mathrm{D}_{2} \mathrm{O} 298 \mathrm{~K}\right): \delta=-13.86 \mathrm{ppm}$. 


\subsubsection{Preparation of aptesSBA-15 support}

SBA-15 was hydrothermally synthesized according to a previously reported procedure. [23] Typically, Pluronic P123 (1.0 g) was dissolved in aqueous $\mathrm{HCl}(2 \mathrm{M}, 30 \mathrm{~mL})$ and distilled water $(7.5 \mathrm{~mL})$ under stirring at $40^{\circ} \mathrm{C}$ and then TEOS $(2.2 \mathrm{~g})$ was added dropwise. The mixture was stirred for $24 \mathrm{~h}$ at $40{ }^{\circ} \mathrm{C}$, and then the temperature was raised to $100{ }^{\circ} \mathrm{C}$ for another $24 \mathrm{~h}$ in a Teflon autoclave. The resulting precipitate was filtered, dried and calcinated at $550{ }^{\circ} \mathrm{C}$ for $5 \mathrm{~h}$ with a ramp of $1^{\circ} \mathrm{C} \mathrm{min}^{-1}$.

The surface of SBA-15 was functionalized via a post-grafting methodology [21] by refluxing the dried SBA-15 support under argon, for $24 \mathrm{~h}$ in dry toluene with 3aminopropyl)triethoxysilane (aptes). The resulting material was filtered, washed with toluene and dried under vacuum at $60^{\circ} \mathrm{C}$ for $2 \mathrm{~h}$. Elemental analysis shows that aptesSBA-15 contains $1.3 \mathrm{mmol}$ of aptes per $\mathrm{g}$ of material.

aptesSBA-15 Anal. Found (\%): N, 2.8.; C, 10.1; H, 2.4; Selected FT-IR( $\left.\mathrm{cm}^{-1}\right)$ : $3421(\mathrm{~m}) ; 2933$ (w); 2360 (w); 2341 (w); 1635 (w); 1199 (sh); 1078 (vs); 970 (sh); 802 (m); 547 (w); 457 (s).

\subsubsection{Preparation of PW ${ }_{11} @ a p t e s S B A-15$ composite}

The immobilization of $\mathrm{PW}_{11}$ in the amine-functionalized SBA-15 was performed via an impregnation method adapted from previously reported procedures $[22,29]$. Briefly, a solution of the potassium salt of the lacunar POM $\left(\left[\mathrm{PW}_{11} \mathrm{O}_{39}\right]^{7-}\right)(1 \mathrm{~g}$ of in $10 \mathrm{~mL}$ of deionized water) was added to aptesSBA-15 ( $0.5 \mathrm{~g}$, previously dried under vacuum at $60{ }^{\circ} \mathrm{C}$ for $2 \mathrm{~h}$ ) and the mixture was stirred for 3 days at room temperature. The solid was separated by filtration, washed with deionized water and dried in a desiccator over silica gel.

PW $11 @$ aptesSBA-15: Anal. Found (\%) W, 19.4; Si, 4.6; loading of POM: 0.096 mmol/g, Si/W (molar) = 1.55; Selected FT-IR (cm ${ }^{-1}$ ): 3445 (vs); 1626 (s); 1505 (w); 1221 (sh); 1085 (vs); 940 (w); 879 (w); 799 (m); 743 (w); 457 (s); selected FT-Raman $\left(\mathrm{cm}^{-1}\right)$ : 2964; 2925; 2914; 1450; 1412; 1327; 1039; 956; 856.

\subsection{Oxidative desulfurization processes (ODS) using model diesel}

A model diesel was prepared by dissolving the most refractory sulfur compounds in

real fuels, namely: 1-benzothiophene (1-BT), dibenzothiophene (DBT), 4methyldibenzothiophene (4-MDBT) and 4,6-dimethyldibenzothiophene (4,6-DMDBT), in $n$ octane with a concentration of approximately $500 \mathrm{ppm}$ each. The ODS experiments were 
conducted in a $5 \mathrm{~mL}$ reactor immersed in a thermostatically controlled liquid paraffin bath at $70{ }^{\circ} \mathrm{C}$, under atmospheric pressure. ODS studies were performed in the absence (solvent-free system) and in the presence of acetonitrile (MeCN) as extraction solvent (biphasic system). Hydrogen peroxide was used as oxidant: $\mathrm{H}_{2} \mathrm{O}_{2} / \mathrm{S}$ molar $=8\left(0.4\right.$ mmol of $\left.\mathrm{H}_{2} \mathrm{O}_{2}\right)$ for the biphasic system and $\mathrm{H}_{2} \mathrm{O}_{2} / \mathrm{S}$ molar $=4\left(0.2 \mathrm{mmol}\right.$ of $\left.\mathrm{H}_{2} \mathrm{O}_{2}\right)$ for the solvent-free system. ODS experiments were performed with the TBA salt of POMs as well as the PW $11 @$ @aptesSBA-15 composite. In a typical biphasic system experiment, 1:1 model diesel/MeCN $(0,75 \mathrm{~mL}$ of each) were added to 3 $\mu \mathrm{mol}$ of POM or to an amount of PW $11 @$ aptesSBA-15 composite containing $3 \mu \mathrm{mol}$ of PW $_{11}$ (31 $\mathrm{mg}$ ). The mixture was stirred for $10 \mathrm{~min}$ at $70{ }^{\circ} \mathrm{C}$ until the initial extraction equilibrium was reached. An aliquot of the upper phase from the model diesel was taken and the oxidative catalytic step was initiated by the addition of the oxidant. The solvent-free system experiments were performed without the presence of the $\mathrm{MeCN}$ and maintaining all the experimental conditions as the biphasic system. In this process only the oxidative catalytic process occurred and at the end of this step the oxidized sulfur compounds present in model diesel were removed by a liquid-liquid extraction. The sulfur content of model diesel was quantified by GC analysis using tetradecane as standard. For the experiments using the heterogeneous catalysts, a centrifugation was carried out to recover the catalyst, which was washed with ethanol and dried in a desiccator over silica gel.

\subsection{Oxidative desulfurization processes (ODS) using untreated diesel}

The untreated diesel was supplied by CEPSA containing $1335 \mathrm{ppm}$ of sulfur. This diesel was tested in both biphasic and solvent-free systems, maintaining the same ratio $\mathrm{H}_{2} \mathrm{O}_{2} / \mathrm{S} /$ catalyst as used in the model diesel experiments. In the biphasic system $10 \mathrm{~mL}$ of diesel (containing about $0,40 \mathrm{mmol}$ of $\mathrm{S}$ ) was added to $10 \mathrm{~mL}$ of $\mathrm{MeCN}$ with the solid catalyst PW $11 @$ aptesSBA-15. This mixture was stirred for $10 \mathrm{~min}$ and then the oxidative catalytic stage was initiated by the addition of the oxidant $\mathrm{H}_{2} \mathrm{O}_{2}$. The real diesel was also desulfurized using the solvent-free system conditions and, in this case, at the end of the oxidative reaction, the treated diesel was subjected to a liquid-liquid extraction with $\mathrm{MeCN}$ or a mixture of $\mathrm{EtOH} / \mathrm{H}_{2} \mathrm{O}_{2}$ 1:1 to remove the oxidized-sulfur compounds. 


\section{Results and discussion}

\subsection{Catalysts characterization}

The PW $11 @$ aptesSBA-15 composite was prepared via an impregnation method, through the incorporation of $\mathrm{PW}_{11}$ anion in a previously amine-functionalized SBA-15 (aptesSBA-15). The prepared composite was characterized by several characterization techniques including vibrational spectroscopy (FT-IR and FT-Raman), powder XRD, inductively coupled plasma optical emission spectrometry (ICP-OES), solid state ${ }^{31} \mathrm{P},{ }^{13} \mathrm{C}$ and ${ }^{29} \mathrm{Si}$ MAS NMR, scanning electron microscopy (SEM), energy dispersive X-ray spectroscopy (EDS) and textural analysis ( $\mathrm{N}_{2}$ adsorption isotherms). The FT-IR spectrum (wavenumber region between 400 and $2800 \mathrm{~cm}^{-1}$ ), display the characteristic bands of the Keggin-type POM derivatives and the SBA-15 support (Figure 1 left). The spectrum of the composite material is dominated by the characteristic bands of the silica support in the region between $400-1100 \mathrm{~cm}^{-1}$, i.e. the typical Si-O-Si bands around 1078, 802 and $457 \mathrm{~cm}^{-1}$, associated with the formation of a condensed silica network. [10, 30, 31] Still in this spectrum, the appearance of two extra bands located at 940 and $879 \mathrm{~cm}^{-1}$ can also be observed, which are attributed to the terminal $v_{\text {as }}\left(W-O_{t}\right)$ and corner-sharing $\mathrm{v}_{\mathrm{as}}\left(\mathrm{W}-\mathrm{O}_{\mathrm{b}}-\mathrm{W}\right)$ vibrational modes, respectively, indicating the presence of $\mathrm{PW}_{11}$ in the composite $[10,19,32]$. As described in the literature, the FT-Raman signal of the silica support is far weaker allowing a better observation of the bands arising from the $\mathrm{PW}_{11}$. Therefore, the bands observed in FT-Raman spectrum of PW $11 @$ aptesSBA-15 (Figure 1 right) located at 1039, 956 and $856 \mathrm{~cm}^{-1}$ are associated to $v_{\text {as }}(P-O), v_{\text {as }}\left(W-O_{t}\right)$ and $v_{\text {as }}\left(W-O_{b}-W\right)$ stretching modes, respectively [24, 32,33]. Additionally, a small shift of these bands to lower wavenumbers was noticed when the $\mathrm{PW}_{11}$ is incorporated in the aptesSBA-15 support. However, this behavior is well reported in the literature for the immobilization of POMs in to silica materials. $[10,29]$ The amount of $\mathrm{PW}_{11}$ incorporated on aptesSBA-15 support was quantified by ICP, revealing a loading of $0.096 \mathrm{mmol}$ per gram of material. 

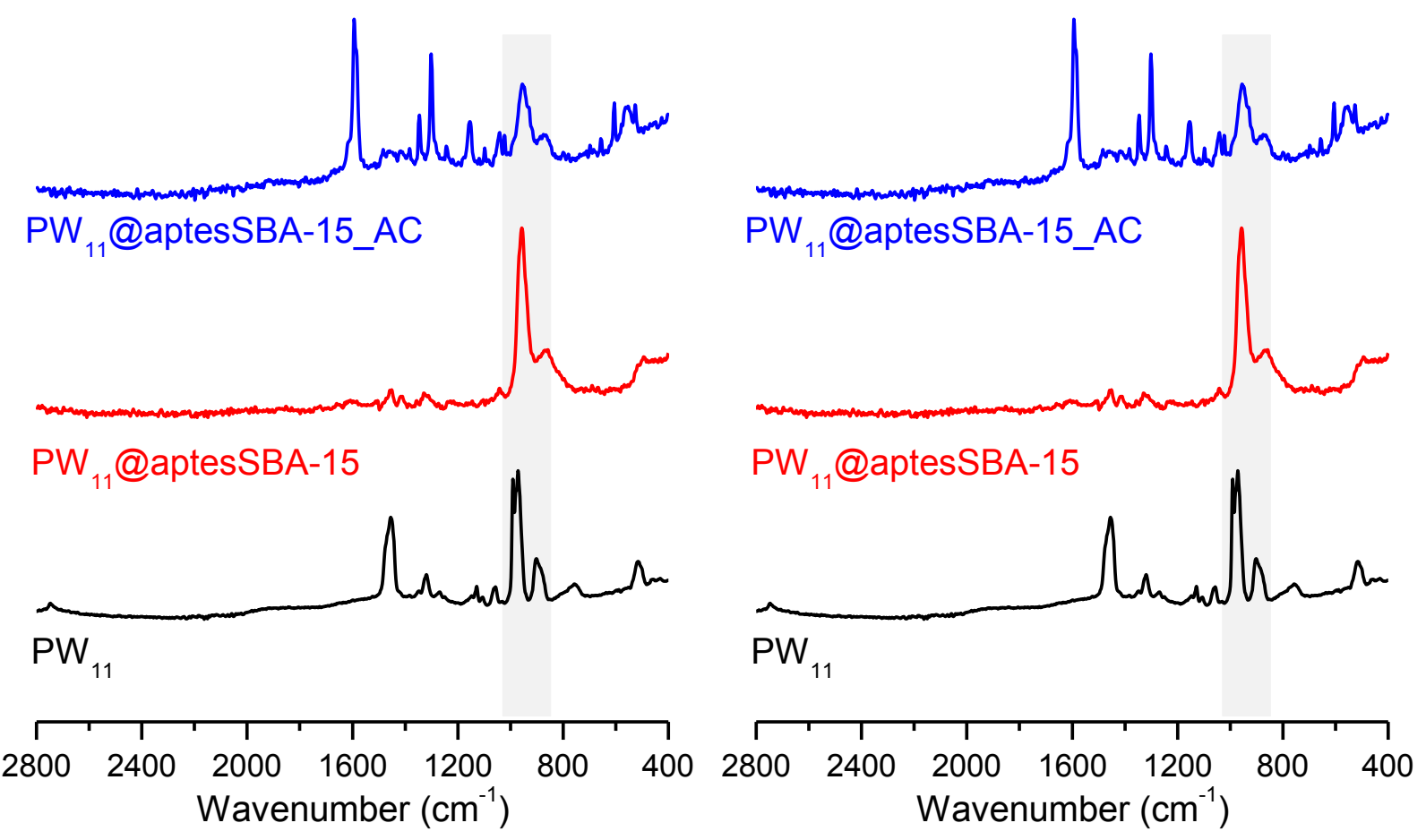

Figure 1: FT-IR (left) and FT-Raman (right) spectra of the isolated PW $_{11}$, the SBA-15, the functionalized support aptesSBA-15 and the composite PW ${ }_{11} @$ aptesSBA-15 before and after catalysis (abbreviated as AC).

The integrity of the lacunar $\mathrm{PW}_{11}$ structure, before and after its incorporation on silica support was investigated by ${ }^{31} \mathrm{P}$ MAS-NMR (Figure 2). The spectrum of the composite material presents a main peak at $-12.73 \mathrm{ppm}$ and the spectrum of the free $\mathrm{PW}_{11}$ display a single peak at $-12.81 \mathrm{ppm}$. These results indicate the maintenance of the $\mathrm{PW}_{11}$ structure after its incorporation on the silica material. $[10,19]$ The PW $_{11} @$ aptesSBA-15 composite was also analyzed by ${ }^{13} \mathrm{C} C P$ MAS-NMR spectroscopy and this spectrum exhibit three peaks located at 43.6, 21.9 and 10.0 ppm (Figure 3). These peaks correspond to the C3, C2 and C1 carbon atoms of the aminopropyl group, respectively, $\mathrm{Si}^{1}{ }^{1} \mathrm{CH}_{2}{ }^{2} \mathrm{CH}_{2}-{ }^{3} \mathrm{CH}_{2}-\mathrm{NH}_{2}$. [24, 34] Moreover, the nonexistence of ${ }^{13} \mathrm{C}$ signals of the $\mathrm{P} 123$ template $(67-77 \mathrm{ppm})$ indicates an efficient removal of the surfactant. [34] 


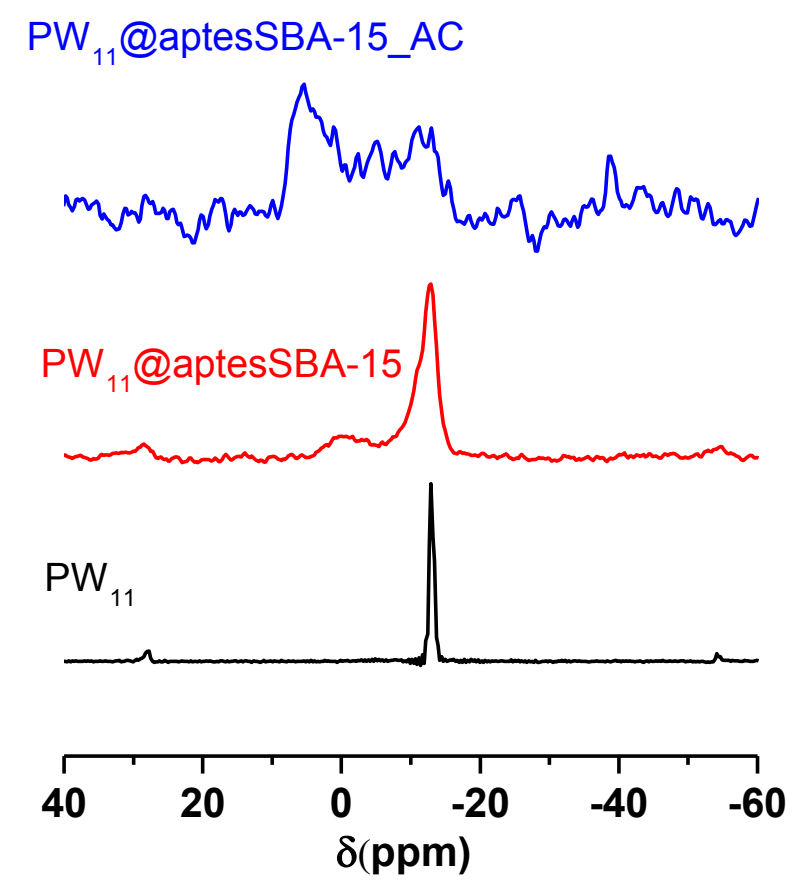

Figure 2: Solid state ${ }^{31} \mathrm{P}$ MAS NMR spectra of the isolated $\mathrm{PW}_{11}$ and the composite PW $11 @ a p t e s S B A-15$ (AC is the abbreviation for after catalysis).

The ${ }^{29}$ Si MAS NMR spectrum of the SBA-15 support reveals a broad and intense band and two shoulders corresponding to $Q^{4}(\delta=-110.61 \mathrm{ppm}), Q^{3}(\delta=-103.44 \mathrm{ppm})$ and $Q^{2}(\delta=-93.14 \mathrm{ppm})$, where $Q^{n}=\mathrm{Si}(\mathrm{OSi})_{4-n}(\mathrm{OH})_{n}, n=2-4$ (Figure 4 left). $[35,36]$ In the ${ }^{29}$ Si MAS NMR spectrum of the amine-functionalized SBA-15, two extra peaks appeared at $-65.68 \mathrm{ppm}$ and $-58.76 \mathrm{ppm}$ related to $T^{3}$ and $T^{2}$ species $\left(T^{n}=\mathrm{CSi}(\mathrm{OSi})_{3-\mathrm{m}}(\mathrm{OH})_{m}, \mathrm{~m}=1-3\right)$, respectively. [37] The appearance of $\mathrm{T}^{2}$ and $\mathrm{T}^{3}$ species suggest the formation of siloxane bonds between Si atoms of aptes and SBA-15. The relative higher intensity of the $T^{3}$ in comparison to $T^{2}$ line is indicative that the aminopropyl functional groups are mainly incorporated in the internal surface of the SBA-15 material. [25, 38-41] The ${ }^{29} \mathrm{Si}$ MAS NMR spectrum of the PW ${ }_{11} @$ aptesSBA-15 composite presents similar profiles to the support aptesSBA-15, indicating that the main structure of the silica material was maintained after $\mathrm{PW}_{11}$ incorporation (Figure 4 left). 


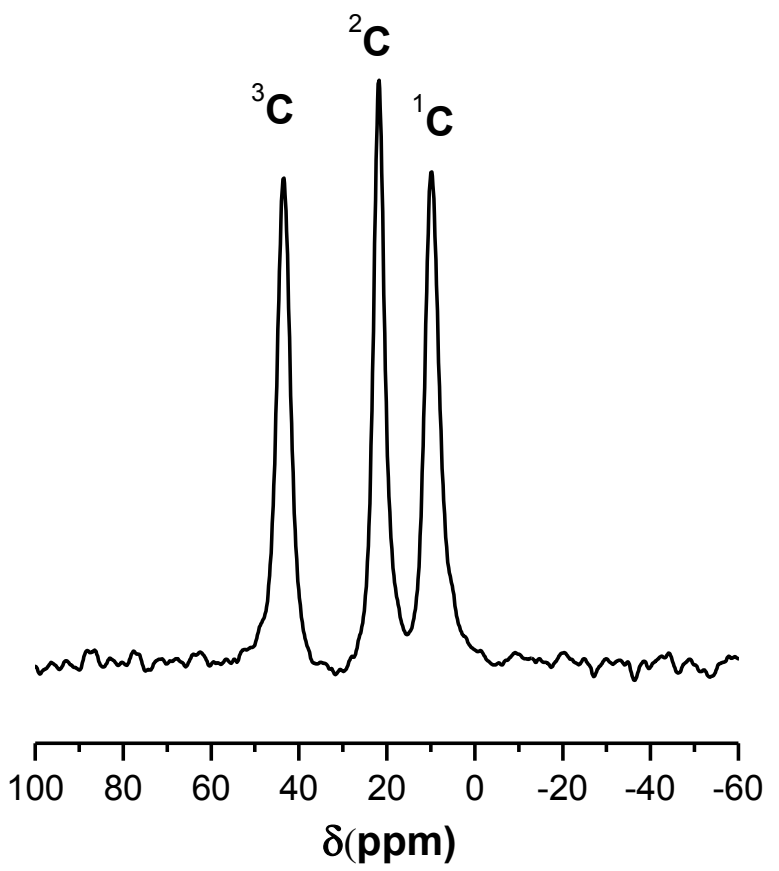

Figure 3: Solid-state ${ }^{13} \mathrm{C}$ CP MAS NMR spectrum of PW ${ }_{11} @$ aptesSBA-15.
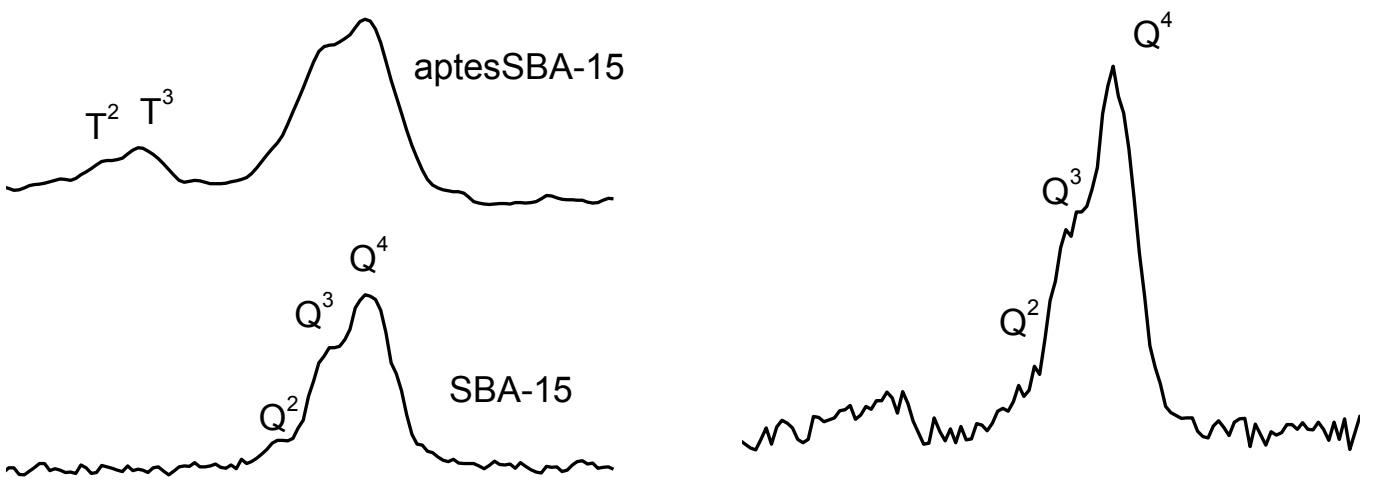

$\mathrm{PW}_{11} @$ aptesSBA-15
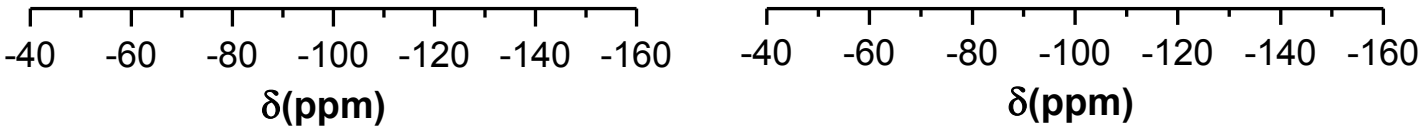

Figure 4: ${ }^{29} \mathrm{Si}$ MAS NMR spectra of the support SBA-15, the functionalized aptesSBA-15 materials and the $\mathrm{PW}_{11} @$ aptesSBA-15 composite.

Figure 5 displays the XRD patterns of the $\mathrm{PW}_{11}$ composite and the support material. The patterns of the SBA-15 and aptesSBA-15 materials are similar, presenting three well-resolved peaks in the low-angle area which are typical of the SBA-15 materials. $[38,41,42]$ These peaks 
correspond to the (100), (110) and (200) reflections of a hexagonal symmetry lattice P6mm characteristic of the SBA-15 material. The peaks of the (110) and (200) reflections in the pattern of the composite materials are shifted to higher $2 \theta$, as observed before in some examples reported in the literature for POMs@SBA-15 composites. [10, 42, 43] The absence of peaks related to the lacunar $\mathrm{PW}_{11}$ strongly indicates its incorporation within the porous channels of the porous support.

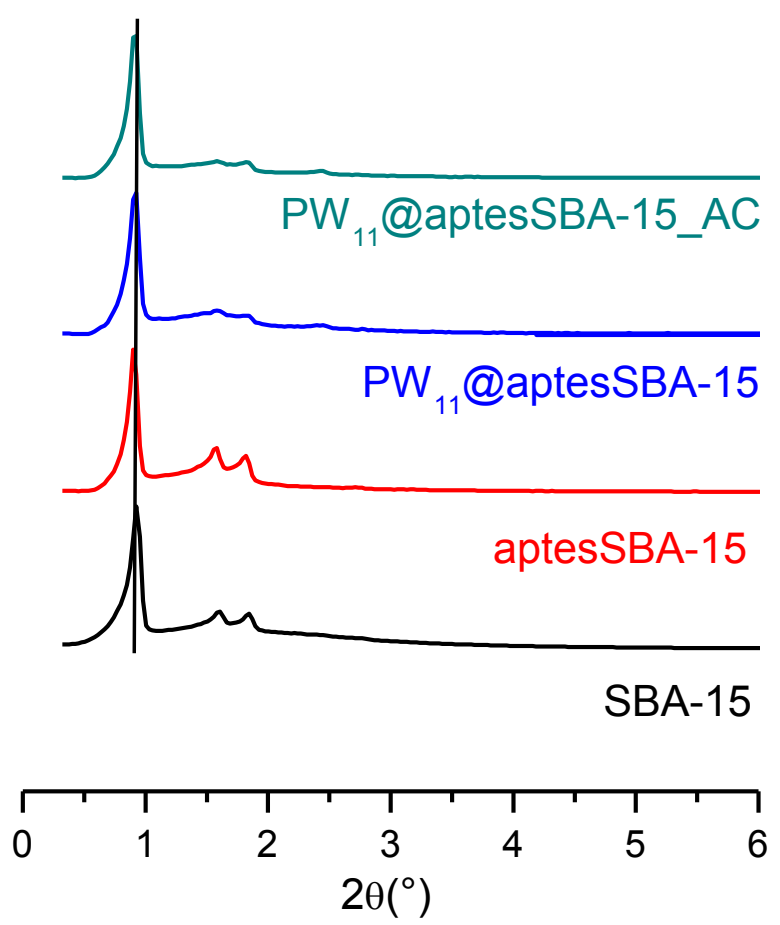

Figure 5: Powder XRD patterns of the support SBA-15, the functionalized aptesSBA-15 and the composite $\mathrm{PW}_{11} @$ aptesSBA-15 before and after catalysis (abbreviated as AC).

The $\mathrm{N}_{2}$ adsorption isotherms are shown in Figure S1 (in the support information ESI) and are of type IV classification with $\mathrm{H} 1$ hysteresis loop typical of these type of mesoporous materials. $[24,26,44]$ The amine-functionalized aptesSBA-15 and the PW $11 @$ aptesSBA-15 materials retain the same shape of the isotherms of bare SBA-15. Besides, there is also a decrease in surface area $\left(A_{B E T}\right)$ and pore volume $\left(V_{\text {total }}\right)$ (Table 1$)$ when going from SBA-15 to aminefunctionalized aptesSBA-15 and finally to the composite, which indicates a successful functionalization with aptes that is anchored on the surface of SBA-15 and also the incorporation of the $\mathrm{PW}_{11}$ on the aptesSBA-15. $[24,29]$ 
Table 1: Textural parameters of SBA-15, aptesSBA-15 and PW $11 @$ aptesSBA-15 composite.

\begin{tabular}{rcc} 
& $\begin{array}{c}A_{\text {BET }} \\
\left(\mathrm{m}^{2} \mathrm{~g}^{-1}\right)\end{array}$ & $\begin{array}{c}\mathbf{V}_{\text {total }} \\
\left(\mathrm{cm}^{3} \mathrm{~g}^{-1}\right)\end{array}$ \\
\hline \hline SBA-15 & 725 & 0,971 \\
aptesSBA-15 & 337 & 0,589 \\
PW $_{11}$ @aptesSBA-15 & 240 & 0,399 \\
\hline \hline
\end{tabular}

The SEM images of the composite material reveal the characteristic morphology of the SBA-15 materials with hexagonal elongated particles with diameters of approximately $950 \mathrm{~nm}$, indicating that the morphology of the silica support was maintained after the $\mathrm{PW}_{11}$ incorporation (Figure 6) $[19,43,45]$ The presence of the $\mathrm{PW}_{11}$ in the composite material could also be confirmed by the presence of the $\mathrm{P}$ and $\mathrm{W}$ elements in the EDS analysis (Figure 6).
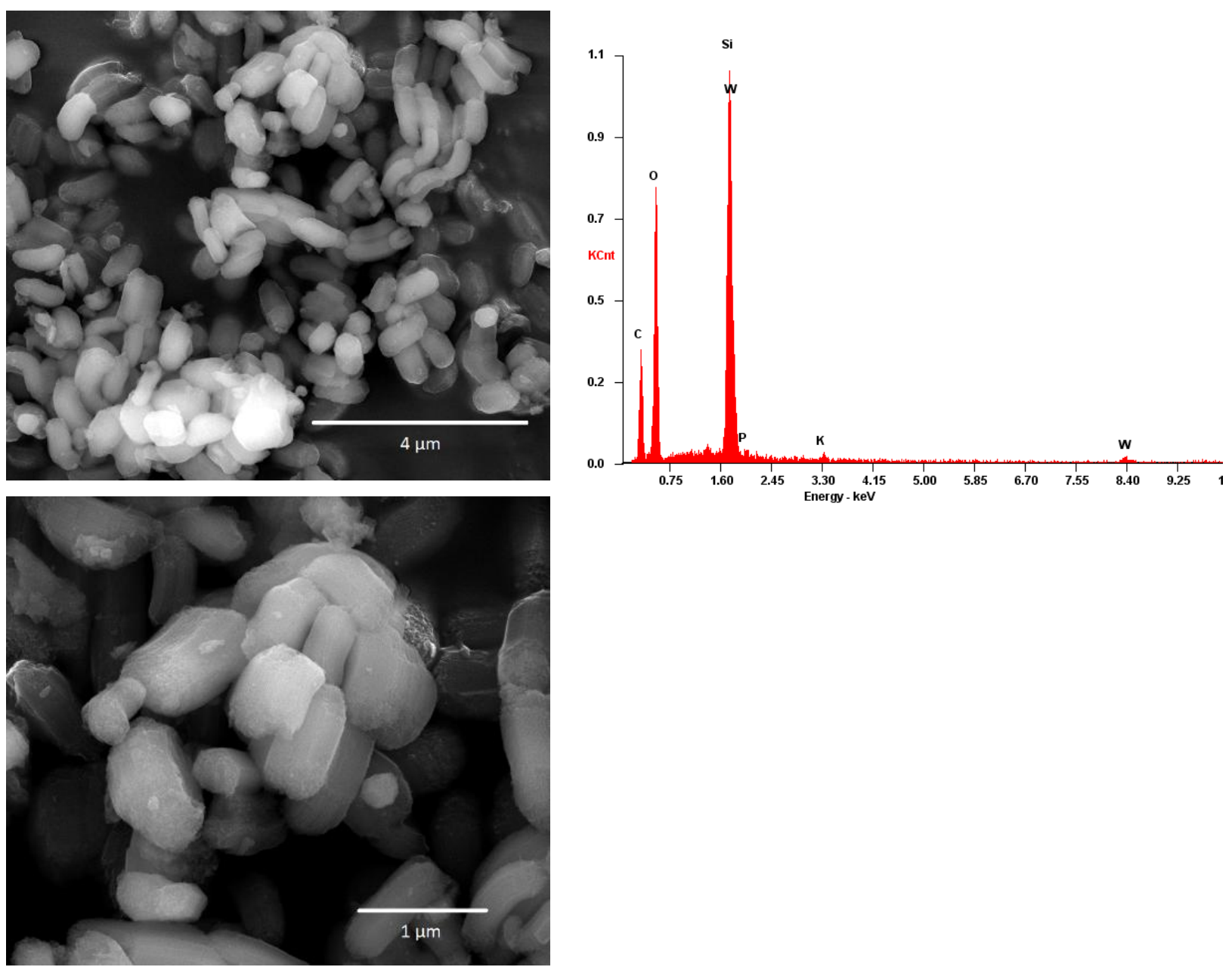

Figure 6: SEM images and EDS spectrum of the PW ${ }_{11} @$ aptesSBA-15 composite. 
In conclusion, the comparative study between the isolated $\mathrm{PW}_{11}$ and its PW $11 @$ aptesSBA-15 composite performed by different techniques indicate a successful immobilization of the $\mathrm{PW}_{11}$ on the amine-functionalized SBA-15 material without degradation of the $\mathrm{PW}_{11}$ structure.

\subsection{Oxidative desulfurization processes using model diesel}

The preliminary studies with the prepared catalysts were performed using a model diesel containing four refractory sulfur compounds usually present in real diesel: 1benzothiophene (1-BT), dibenzothiophene (DBT), 4-methyldibenzothiophene (4-MDBT) and 4,6-dimethyldibenzothiophene (4,6-DMDBT), with an individual concentration of approximately $500 \mathrm{ppm}$. The desulfurization studies were performed initially using various homogeneous catalysts based in TBA salts of various Keggin derivative POMs: the Keggin anion $\mathrm{PW}_{12}$, the lacunar $\mathrm{PW}_{11}$ and the mono-substituted $\mathrm{PW}_{11} \mathrm{Zn}$. These studies were performed using a biphasic system (1:1 model diesel/MeCN extraction solvent) that consisted in an initial liquid-liquid extraction ( 10 min of stirring at $70^{\circ} \mathrm{C}$ ), followed by an oxidative catalytic stage (ratio $\mathrm{H}_{2} \mathrm{O}_{2} / \mathrm{S}=8$, at $70{ }^{\circ} \mathrm{C}$ ). The heterogeneous catalytic performance of $\mathrm{PW}_{11} @$ aptesSBA-15 composite was also investigated using the biphasic system, and also in a solvent-free system. In this system, the sulfur catalytic oxidation takes place without the presence of any extraction solvent, followed by a liquid-liquid extraction to remove the oxidized sulfur from diesel. This final extraction was performed using $\mathrm{MeCN}$ or a greener solvent, such as ethanol and/or water. [27]

\subsubsection{Homogeneous catalysts: activity and stability}

The homogeneous desulfurization catalytic studies, using the TBA salts of the different Keggin-type POMs were performed in two stages: an initial liquid-liquid extraction and an oxidative catalytic stage. In the initial extraction, non-oxidized sulfur compounds were transferred from the model diesel to the polar organic phase (MeCN). After $10 \mathrm{~min}$ the sulfur transfer equilibrium was reached and the oxidative catalytic step was initiated by the addition of the oxidant $\left(\mathrm{H}_{2} \mathrm{O}_{2}\right)$. In this stage the sulfur compounds were oxidized to the correspondent sulfoxides and/or sulfones, which remained in the extraction phase.

Figure 7 displays the desulfurization profiles catalyzed by the different Keggin derivative compounds. The initial extraction step was responsible for the major removal of sulfur from 
the model diesel to the MeCN phase. The initial desulfurization efficiency was similar for the various POM catalysts (from $53.0 \%$ to $58.0 \%$ ), which indicates that the structure of the homogeneous POMs does not have any influence in this step of the process. To increase the desulfurization, the oxidant was added to procedure the catalytic sulfur-oxidation step. It can also be observed that the lacunar $\mathrm{PW}_{11}$ was the most active catalyst reaching ultra-low levels $(<10 \mathrm{ppm})$ after $2 \mathrm{~h}$ of reaction (99.7\% of total desulfurization). Instead of it, the Keggin structure $\mathrm{PW}_{12}$ was the less efficient homogeneous catalyst reaching only $68.0 \%$ of total desulfurization after $2 \mathrm{~h}$ of reaction and only $28.1 \%$ of oxidative desulfurization was achieved, in the catalytic stage of the process. The zinc-substituted POM $\left(\mathrm{PW}_{11} \mathrm{Zn}\right)$ achieved $94.0 \%$ of desulfurization after the same period of time. It is important to note, that after the addition of the aqueous $\mathrm{H}_{2} \mathrm{O}_{2}$ oxidant (10 min of the process) a decrease of desulfurization was observed using Keggin $\mathrm{PW}_{12}$ and zinc-substituted $\mathrm{PW}_{11} \mathrm{Zn}$ catalysts. This is probably caused by the water introduced in the biphasic system after the addition of the aqueous oxidant, associated to the lower oxidative catalytic efficiency of these two catalysts. This behavior was previously reported by our group using similar biphasic systems. [19] The low reactivity of $\mathrm{PW}_{12}$ in $\mathrm{MeCN}$ medium has been already reported and justified by the difficult formation of active species. [10]

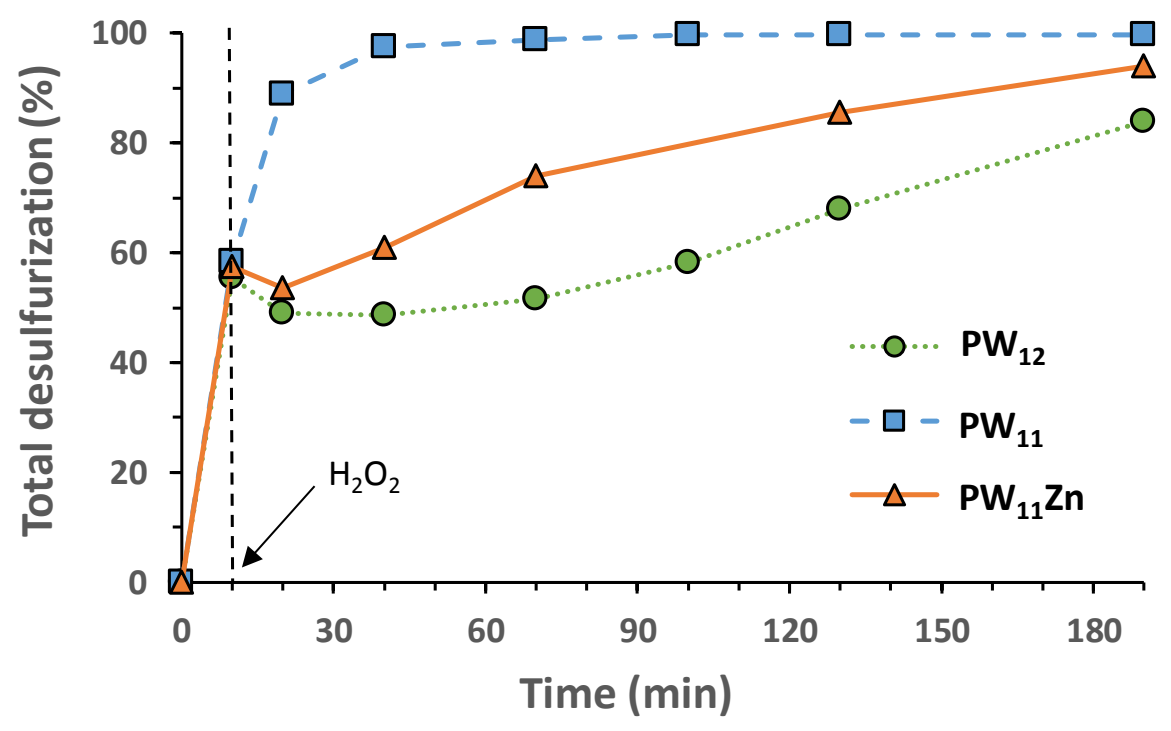

Figure 7: Desulfurization profile of the multicomponent model diesel in the presence of different homogeneous catalysts, $\mathrm{PW}_{12}, \mathrm{PW}_{11}$ and $\mathrm{PW}_{11} \mathrm{Zn}$, using $\mathrm{MeCN}$ as extraction solvent and $\mathrm{H}_{2} \mathrm{O}_{2} / \mathrm{S}=8$, at $70^{\circ} \mathrm{C}$. 
To understand the correlation between POMs catalytic activity and their structure, i.e. complete Keggin structure $\left(\mathrm{PW}_{12}\right)$, the Keggin structure losing a WO ${ }^{4+}$ unit $\left(\mathrm{PW}_{11}\right)$ and also the incorporation of a zinc metallic center in the lacunary space of the lacunar structure $\left(P W_{11} Z n\right)$, the analysis of ${ }^{31} \mathrm{P}$ NMR from the polar organic reaction medium (MeCN phase containing the POM) was performed at the end of the process (Figure S2 in ESI). The spectrum of PW 12 reveals a single peak at $-13.86 \mathrm{ppm}$ which is similar to the spectrum before catalysis. This result indicates that the Keggin structure is stable since does not suffer any degradation but also this is the less active POM. For the zinc substituted $\mathrm{PW}_{11} \mathrm{Zn}$, the ${ }^{31} \mathrm{P} N \mathrm{NR}$ spectrum after catalytic use presents a peak at $-10.59 \mathrm{ppm}$ is indicating that the zinc-substituted structure is stable despite being active under the used catalytic conditions. Therefore, the substitution of a tungsten atom by a zinc atom in the Keggin structure produces an appreciable increase of catalytic activity. In fact, the higher catalytic activity observed for the $\mathrm{PW}_{11} \mathrm{Zn}$ instead of the low performance attributed to the Keggin $\mathrm{PW}_{12}$ can be attributed to the facility of $\mathrm{PW}_{11} \mathrm{Zn}$ structure to form active peroxo intermediates by the interaction of the labile water ligand coordinated to the zinc metal. The formed active peroxo intermediates can easily oxidize the sulfur compounds. $[27,46]$

In the case of lacunar $\mathrm{PW}_{11}$, the ${ }^{31} \mathrm{P}$ NMR spectrum after catalysis shows that the original peak at $-11.41 \mathrm{ppm}$ is shifted to $-13.86 \mathrm{ppm}$ and a smaller peak appears at $4.49 \mathrm{ppm}$ (Figure $\mathrm{S} 2$ in ESI). This last peak can be assigned to $\left[\mathrm{PO}_{4}\left\{\mathrm{~W}\left(\mathrm{O}_{2}\right)_{2}\right\}_{4}\right]^{3-}$ Venturello complex. [47, 48] The peak observed at $-13.86 \mathrm{ppm}$ was suggested previously by our group to be assigned as a $\mathrm{PW}_{\mathrm{x}} \mathrm{O}_{\mathrm{y}}$-type anion considered to be an intermediated to synthesize the Venturello peroxocomplex. [49-51]

\subsubsection{Homogeneous vs Heterogeneous lacunar catalysts}

The most active catalyst in the homogeneous studies $\left(\mathrm{PW}_{11}\right)$ was incorporated in an amine functionalized aptesSBA-15 to prepare a heterogeneous catalyst that could be easily recovered from the desulfurization system after the experiments. The PW ${ }_{11} @ a p t e s S B A-15$ heterogeneous catalyst was tested in the biphasic system using the same conditions of the homogeneous catalytic studies. Figure 8 shows the desulfurization profiles of a multicomponent model diesel, with approximately $2000 \mathrm{ppm}$ of sulfur, catalyzed by the solid PW $11 @$ aptesSBA-15 and the homogeneous lacunar PW PW $_{11}$. The initial extraction of sulfur compounds from model diesel to the $\mathrm{MeCN}$ phase $\left(10 \mathrm{~min}\right.$ at $\left.70^{\circ} \mathrm{C}\right)$ was similar using both catalysts (total desulfurization of $58,5 \%$ for the homogeneous $\mathrm{PW}_{11}$ catalyst and $55,1 \%$ for the 
PW $11 @$ aptesSBA-15 composite). The transfer of sulfur compounds from the model diesel to the solvent phase follows the previously reported order: 1-BT > DBT > 4-MDBT > 4,6-DMDBT (Figure S3 in ESI). [10, 19] In fact, the initial liquid-liquid extraction step (10min) is responsible for the major removal of sulfur. In this step, 1-BT is the sulfur compound most efficiently removed due to its low molecular diameter. However, its low electron density on the sulfur atom, when compared with the other sulfur compounds, makes it less reactive in the oxidation step and therefore more difficult to be completely oxidized and removed. The other studied sulfur compounds have similar sulfur electron densities; however, DBT is more soluble in MeCN than the other dibenzothiophene derivatives and the methyl derivatives (4-MDBT and 4,6-DMDBT) present some steric hindrance by the methyl groups. [10, 19, 46]

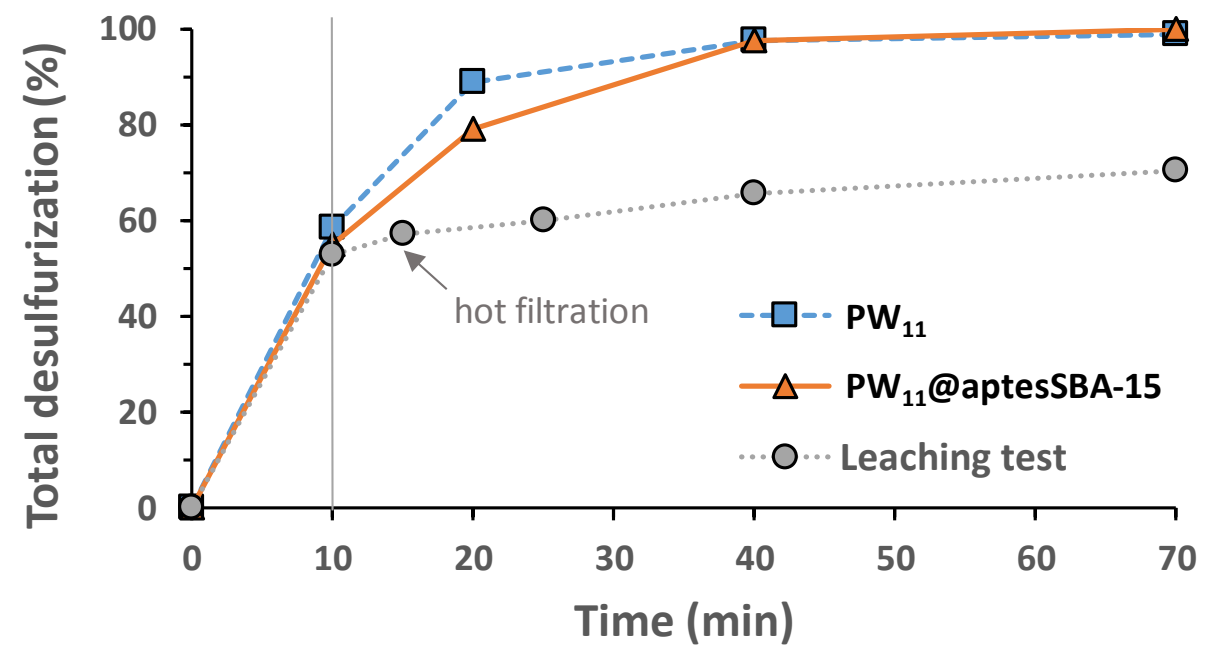

Figure 8: Desulfurization profile of the model diesel using the homogeneous $\mathrm{PW}_{11}$ and the heterogeneous PW $11 @$ aptesSBA catalysts.

Figure S3 shows that the sulfur compounds more difficult to oxidize in the biphasic system follows the order $1-\mathrm{BT}<4,6-\mathrm{DMDBT}<4-\mathrm{MDBT}<\mathrm{DBT}$. After $30 \mathrm{~min}$ of oxidation, total desulfurization was achieved for DBT and 4-MDBT, using PW $_{11}$ and PW $_{11} @$ aptesSBA-15 catalysts. The 4,6-DMDBT reached $99.0 \%$ of desulfurization using the heterogeneous catalyst and $98.9 \%$ when the homogeneous catalyst was used. In the case of 1-BT, which was the most difficult to oxidize, the obtained desulfurization was $91.8 \%$ for the heterogeneous catalyst and $83.0 \%$ for the homogeneous. Figure 8 presents similar total desulfurization profiles for the homogeneous $\mathrm{PW}_{11}$ and the heterogeneous $\mathrm{PW}_{11} @$ aptesSBA-15 catalysts and practically complete desulfurization was achieved after 60 minutes of oxidation (97\% using the 
homogeneous catalyst and $100 \%$ using the heterogeneous catalyst). Therefore, both catalyst present similar oxidative catalytic performance; however, the PW ${ }_{11} @$ aptesSBA has the advantage of being easily recovered from the system at the end and able to be reused in a new cycle. To investigate a possible leaching of the active catalytic centers, the heterogeneous catalyst was separated from the medium reaction by hot filtration after $15 \mathrm{~min}$ ( $5 \mathrm{~min}$ after the addition of oxidant). The results show that the oxidation practically stops after catalyst removal (Figure 8) what confirms catalyst heterogeneity.

\subsubsection{Biphasic vs Solvent-free systems using PW ${ }_{11} @ a p t e s S B A-15$ catalyst}

The oxidative catalytic performance of the heterogeneous catalyst PW $11 @$ aptesSBA-15 was also evaluated in the solvent-free system and compared with the biphasic system (reported in 3.2.2). The kinetic profiles for the desulfurization of the multicomponent model diesel using the solvent-free and biphasic systems are presented in Figure 9. Both systems exhibit similar profiles and were able to achieve complete desulfurization after just $60 \mathrm{~min}$ of reaction. The homogeneous $\mathrm{PW}_{11}$ catalyst tested under the solvent-free conditions only reached $51.6 \%$ of total conversion for the same period of time and only $68.7 \%$ after $120 \mathrm{~min}$ (Figure S4 in ESI). The use of PW PW $_{11}$ aptesSBA-15 composite in the solvent-free conditions has the advantage of reaching total oxidation of sulfur compounds without the need of a polar organic solvent. Besides, the final extraction of the oxidized products can be conducted with a choice of more sustainable and more cost-effective solvents. This is an important point of view for the future industrial application.

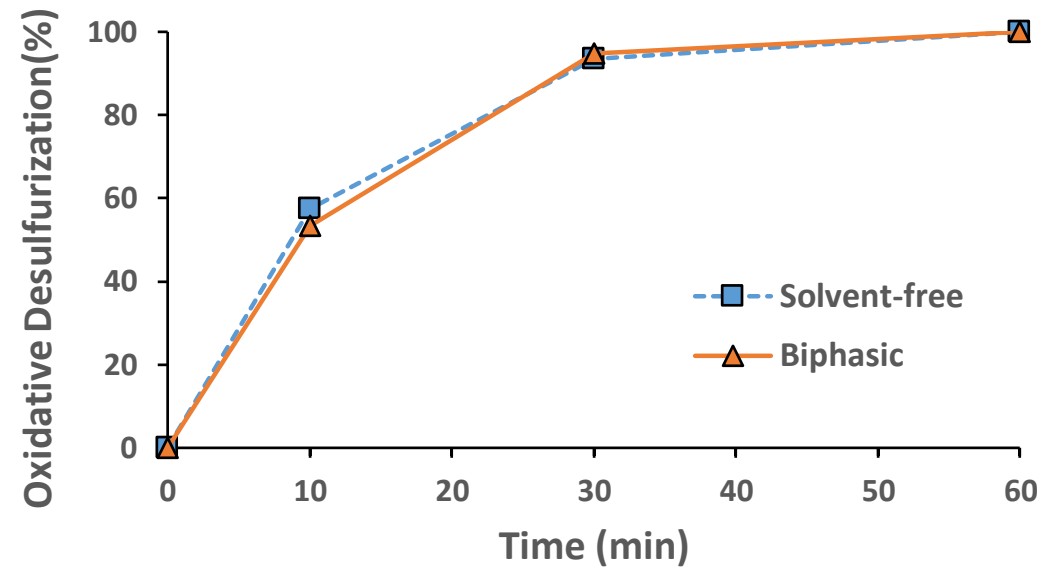

Figure 9: Kinetic profiles for the desulfurization of a model diesel using the solvent-free or biphasic systems with PW $11 @ a p t e s S B A-15$ composite. 
The solvent-free system was submitted to an optimization concerning the catalyst and oxidant amounts. Two different amounts of composite catalyst were used in the ODS solventfree process optimization $\left(1 \mu \mathrm{mol}\right.$ and $3 \mu \mathrm{mol}$ ) and these were tested using a ratio $\mathrm{H}_{2} \mathrm{O}_{2} / \mathrm{S}$ of 2 , 4 and 8 , at $70^{\circ} \mathrm{C}$. The optimization results are presented in Figure S5 in ESI. It was possible to observe that using the lowest amount of oxidant $\left(\mathrm{H}_{2} \mathrm{O}_{2} / \mathrm{S}=2\right)$ the total oxidation of sulfur compounds was not achieved. Using the highest ratio $\left(\mathrm{H}_{2} \mathrm{O}_{2} / \mathrm{S}=8\right)$ total conversion was achieved after $90 \mathrm{~min}$. However, the optimum $\mathrm{H}_{2} \mathrm{O}_{2} / \mathrm{S}$ ratio was considered to be 4 , since complete conversion was achieved after only 60 min (using $3 \mu \mathrm{mol}$ of catalyst). When the amount of catalyst was decreased from 3 to $1 \mu \mathrm{mol}$ of active catalytic center, total oxidation was achieved after only $90 \mathrm{~min}$. Therefore, the optimized system should use $3 \mu \mathrm{mol}$ of active catalytic center and a ratio $\mathrm{H}_{2} \mathrm{O}_{2} / \mathrm{S}=4$. The heterogeneous catalyst $\mathrm{PW}_{11} @$ aptesSBA-15 was tested using this solvent-free optimized conditions in the biphasic system and the results revealed that this system was less effective than the reported above (using $\mathrm{H}_{2} \mathrm{O}_{2} / \mathrm{S}=8$ ) reaching $97,1 \%$ after $60 \mathrm{~min}$ of oxidation and 99,7\% after $120 \mathrm{~min}$. These results show that the solventfree system has an extra advantage of using less oxidant amount to achieve total desulfurization in $60 \mathrm{~min}$.

Recently our research group has reported the incorporation of another POM anion $\left(\left[\mathrm{Eu}\left(\mathrm{PW}_{11} \mathrm{O}_{39}\right)_{2}\right]^{11-}\right)$ in the same support aptesSBA-15 and evaluated its application in the desulfurization of a multicomponent model diesel. [24] The catalyst performance was evaluated in a biphasic system and also in a solvent- free system. The best performance was achieved for the solvent-free system with complete desulfurization after $2 \mathrm{~h}$. Therefore, the replacement of the lanthanide-sandwich polyanion by a simple lacunar $\mathrm{PW}_{11}$ increased the desulfurization and the catalytic efficiency.

\subsection{Recycling capacity and stability of PW $\mathrm{P}_{11} @ a p t e s \mathrm{SBA}-15$}

The recycle capacity of the heterogeneous catalyst PW $11 @$ aptesSBA-15 was investigated in biphasic and solvent-free desulfurization systems. In both systems, $3 \mu \mathrm{mol}$ of catalyst were used and ratios $\mathrm{H}_{2} \mathrm{O}_{2} / \mathrm{S}$ of 8 and 4 were used for the biphasic and solvent-free systems, respectively. The recycling ability of the heterogeneous catalyst was evaluated for eight consecutive cycles under biphasic system. After each cycle, the solid catalyst was recovered, washed with ethanol, dried and reused in a new desulfurization cycle maintaining the same experimental conditions. Figure 10 display the desulfurization results obtained for 
the consecutive cycles after $1 \mathrm{~h}$ of oxidation. It can be observed that the catalyst maintained its performance during all the cycles and no loss of catalytic activity was detected.

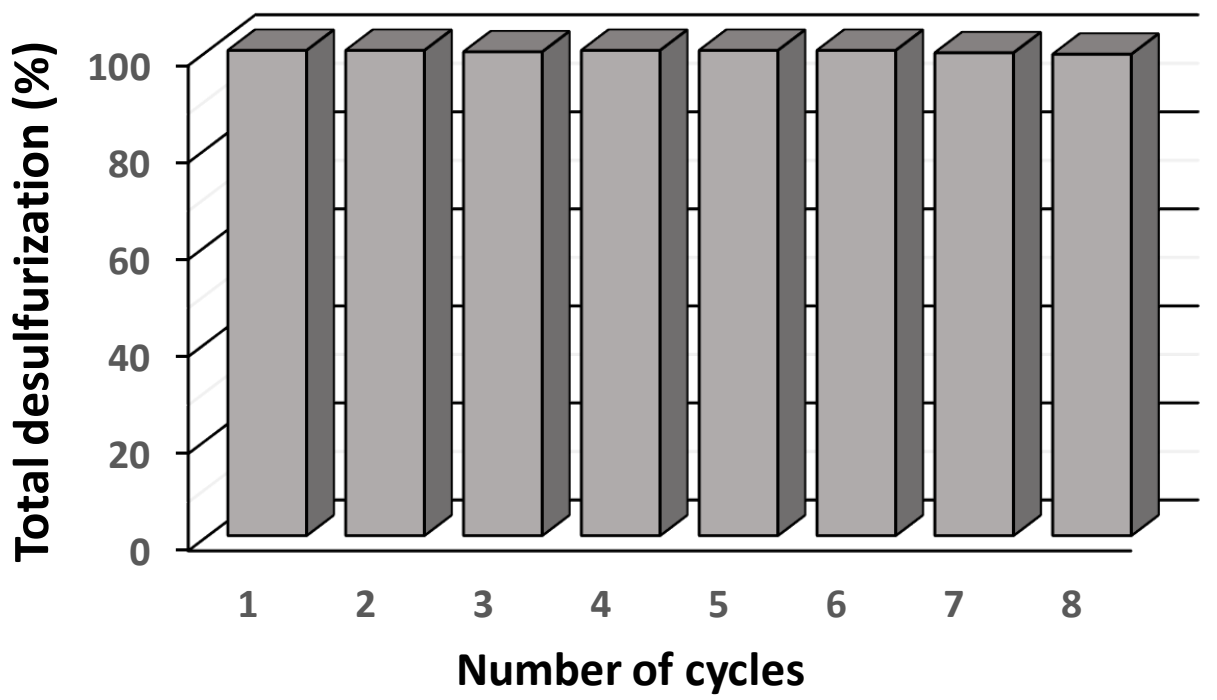

Figure 10: Desulfurization results of a multicomponent model diesel after $1 \mathrm{~h}$, performed for eight consecutive cycles, using the biphasic system diesel/MeCN (1:1) and $\mathrm{H}_{2} \mathrm{O}_{2} / \mathrm{S}=8$, catalyzed by PW $11 @ a p t e s S B A-15$

The recycling ability of the $\mathrm{PW}_{11} @$ aptes SBA-15 catalyst was also tested in the solventfree conditions, i.e. in the absence of $\mathrm{MeCN}$ extraction solvent. At the end of each cycle the catalyst was recovered by centrifugation, washed with ethanol and dried to be used in a new oxidative desulfurization cycle under the same reaction conditions. At the end of the oxidative step, a liquid-liquid extraction (1:1 model diesel/MeCN or Ethanol/water) was performed during $10 \mathrm{~min}$ at room temperature, in order to remove the oxidized sulfur compounds from model diesel. Figure 11 presents the oxidative desulfurization data for eight consecutive cycles. The results reveal similar catalytic performances along the cycles and without apparent loss of catalytic activity. 


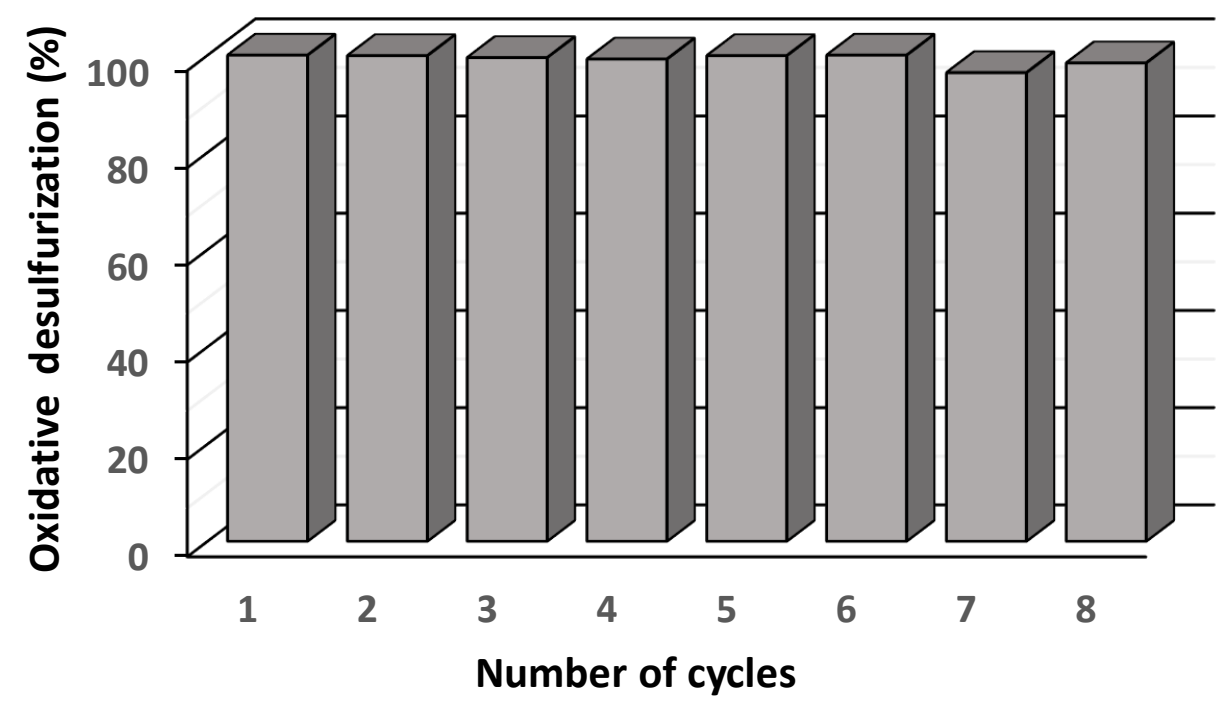

Figure 11: Results obtained for eight ODS cycles after $1 \mathrm{~h}$ catalyzed by $\mathrm{PW}_{11} @$ aptesSBA composite using the solvent-free system and $\mathrm{H}_{2} \mathrm{O}_{2} / \mathrm{S}=4$

The stability of the PW $11 @$ aptes SBA-15 composite after catalytic use was investigated using several techniques. The catalyst was retrieved after one desulfurization cycle performed in biphasic and also in solvent-free system. The recovered solids were analyzed by ICP-OES that reveals that the catalyst presents similar Si/W (molar) ratio before (1.55) and after catalysis (1.65), under the solvent free system, indicating that practically no loss of active POM center occurred during reaction. The same analysis was performed using the solid recovered from the biphasic system; however, in this case some leaching was detected since the Si/W (molar) ratio increased from 1.55 to 2.28 after catalysis. The same recovered solid was also analyzed by powder X-ray diffraction, vibrational spectroscopy (FT-IR and FT-Raman), SEM/EDS and ${ }^{31} \mathrm{P}$ MAS NMR. The powder X-ray patterns of the PW ${ }_{11} @$ aptesSBA-15 before and after oxidative catalysis exhibit identical profiles concerning the position and diffraction peaks relative intensity (Figure 5). The FT-IR spectrum of PW $11 @$ aptesSBA-15_AC (AC is the abbreviation for after catalysis) (Figure 1 left) reveals that the characteristic bands of the POM, in particular in the region of $800-900 \mathrm{~cm}^{-1}$, were maintained, which can indicate that the POM structure was maintained after catalytic use. Besides, the FT-Raman spectrum of the composite after catalytic use (Figure 1 right) also points out to the preservation of the POM structure, since the bands assigned to the POM stretching modes $\left(990-959 \mathrm{~cm}^{-1}\right)$ are still preserved. The bands that appear in the $1200-1700 \mathrm{~cm}^{-1}$ region in the FT-Raman spectrum are most likely related to the presence of oxidized sulfur compounds from model diesel that remained adsorbed on the catalyst as previously observed. $[20,24]$ In fact, the SEM/EDS results reveal the presence of sulfones in the composite after catalysis (Figure S6 in ESI). The SEM images show that the 
material has maintained its morphology with no visible degradation of the silica support, besides it can be observed the presence of sulfur compounds adsorbed on the composite. This fact is also evident in the EDS spectrum in Z1 zone, where the sulfur presence is reveled. The EDS analysis of the PW $11 @$ aptesSBA-15_AC also shows well the presence of tungsten from the

POM. The ${ }^{31} \mathrm{P}$ MAS NMR analysis of the composite after catalytic use demonstrates the appearance of a small peak at $-12.91 \mathrm{ppm}$, assigned to the starting $\mathrm{PW}_{11}$ structure (Figure 2). Another peak shows up at $5.59 \mathrm{ppm}$, which indicates the occurrence of a transformation of the lacunar $\mathrm{PW}_{11}$ structure in a new active specie that must be assigned to a peroxopolyoxometalate such as $\left\{\mathrm{HPO}_{4}\left[\mathrm{~W}(\mathrm{O})\left(\mathrm{O}_{2}\right)_{2}\right]_{2}\right\}^{2-}$. [52] This result reveals the low stability of the lacunar structure even when immobilized on a functionalized aptesSBA-15 support. The new specie formed may also be catalytically active since no loss of activity was detected in the recycling studies.

\subsection{Desulfurization of CEPSA untreated diesel}

The remarkable oxidative catalytic performance of PW $11 @$ aptesSBA-15 composite to desulfurize the model diesel has led to its application in the desulfurization of an untreated real diesel supplied by CEPSA (containing 1335 ppm of total sulfur). The analysis by GC-FID/SCD of this diesel reveals a high diversity of sulfur compounds (Figure S7 in ESI). The desulfurization experiments were performed using the biphasic system (1:1 diesel/MeCN) and also solventfree system (Table 2). In this last case a final liquid-liquid extraction with MeCN and 1:1 $\mathrm{EtOH} / \mathrm{H}_{2} \mathrm{O}$ was performed to remove the oxidized sulfur compounds.

Table 2 reveals that the highest desulfurization efficiency was achieved using the biphasic system (83.4\%), performing an initial extraction with MeCN for $10 \mathrm{~min}$ and also using this solvent 1:1 with real diesel during oxidative catalytic step. For the solvent-free system, without performing any initial diesel extraction, the desulfurization efficiency reached only $23.1 \%$. In this case, the majority of the sulfur oxidized compounds still remain in the diesel. However, the $23.1 \%$ of desulfurization is indicative of some possible sulfur compounds adsorption on the composite, which was confirmed to occur by SEM analysis (Figure S6 in SI). When a final extraction was performed for 10 min with $\mathrm{EtOH} / \mathrm{H}_{2} \mathrm{O}_{2}(1: 1)$, the desulfurization efficiency increased from $23.1 \%$ to $43.1 \%$. However, using MeCN as final extraction solvent the desulfurization efficiency achieved $72.2 \%$. 
Table 2: Results of the experiments for desulfurization of untreated real diesel obtained after 2 hours of oxidation, at $70^{\circ} \mathrm{C}$.

\begin{tabular}{cc}
\hline \hline $\begin{array}{c}\text { Diesel sulfur content } \\
(\mathrm{ppm})\end{array}$ & $\begin{array}{c}\text { Total desulfurization } \\
(\%)\end{array}$ \\
\hline 1026 & 23.1 \\
\hline 759 & 43.1 \\
\hline 374 & 71.9 \\
\hline 222 & 83.4 \\
\hline
\end{tabular}

Since the biphasic system was the most efficient to desulfurize the real diesel, the heterogeneous catalyst was recycled for three consecutive cycles. After each cycle the catalyst was recovered by filtration, washed with ethanol and dried to be used in a new cycle under the same reaction conditions. Figure S8 in ESI presents the results obtained for three consecutive cycles after $3 \mathrm{~h}$ of reaction. The desulfurization efficiency was maintained during the 3 cycles, indicating that the catalyst performance was retained and can be used to desulfurize continuously various aliquots of untreated diesel.

\section{Conclusions}

This work presents the investigation of various Keggin polyoxometalates derivatives as homogeneous catalysts for the oxidative desulfurization of a multicomponent model diesel formed by the most refractory sulfur compounds. An efficient catalytic performance was only observed using a biphasic diesel/acetonitrile system with a ratio $\mathrm{H}_{2} \mathrm{O}_{2} /=8$ and $3 \mu \mathrm{mol}$ of catalyst at $70{ }^{\circ} \mathrm{C}$. Structural modifications performed in the Keggin-type compound $\left(\mathrm{PW}_{12}\right)$, such as the removal of a $\mathrm{WO}^{4+}$ unit, forming the lacunar $\mathrm{PW}_{11}$ compound and the substitution of a tungsten atom by a zinc metal center, to form $\mathrm{PW}_{11} \mathrm{Zn}$, provided a significant increase in the catalytic activity. The most active catalyst was the lacunar $\mathrm{PW}_{11}$ compound, achieving a total desulfurization after only $60 \mathrm{~min}$ of reaction. However, this compound showed low structural stability after catalytic use and the Venturello peroxocomplex was identified as the active catalytic specie. To investigate the stability and the activity of the lacunar PW 11 in the solid state, this homogeneous $\mathrm{PW}_{11}$ was immobilized by a post-grafting method on an aminefunctionalized SBA-15. The catalytic activity of the composite PW ${ }_{11} @ a p t e s S B A-15$ was similar 
to the homogeneous $\mathrm{PW}_{11}$ under the biphasic diesel/acetonitrile system. Furthermore, the composite also presents a high oxidative desulfurization performance in a solvent-free system, i.e. without the need of acetonitrile. In this case, complete desulfurization was also achieved after 60 min and half amount of oxidant was used (ratio $\mathrm{H}_{2} \mathrm{O}_{2} / \mathrm{S}=4$ ). The PW $\mathrm{P}_{11} @$ aptesSBA-15 composite was also used as catalyst for the oxidative desulfurization of a real unthread diesel. Experiments performed under biphasic system (1:1 diesel/acetonitrile) originated higher desulfurization efficiency (83.4\%) than the solvent-free system (71.9\%); however, double amount of oxidant was consumed in the first case. The recycle capacity of the composite was confirmed for eight consecutive cycles in both systems and its stability showed to be higher under the solvent-free system than the biphasic system. In the first case, low leaching of polyoxometalate active species was observed. Finally, the composite showed to have interesting adsorptive capacity to oxidized-sulfur compounds. Therefore, the solvent-free desulfurization system seems to be more advantageous than the biphasic since promotes the stability of the active catalyst and the use of less excess of oxidant.

\section{Acknowledgements}

This work was partly funded through the projects REQUIMTE-LAQV [FCT (Fundação para a Ciência e a Tecnologia) Ref. LAQV, REQUIMTE (POCI-01-0145-FEDER-007265, UID/QUI/50006/2013)] and CENIMAT, I3N (POCI-01-0145-FEDER-007688, UID/CTM/50025/2013) and UID/MULTI/00612/2013 (CQB), financed by national funds through the FCT/MEC and when appropriate co-financed by the Fundo Europeu de Desenvolvimento Regional (FEDER) under the PT2020 Partnership Agreement. The FCT and the European Union are acknowledged for the post-graduation grants SFRH/BD/95571/2013 (to SOR) and SFRH/BPD/73191/2010 (to CMG) co-funded by Ministério da Ciência, Tecnologia e Ensino Superior (MCTES) and the European Social Fund through the program POPH of QREN. The authors also acknowledge the Portuguese Nuclear Magnetic Resonance Network (PTNMR). 


\section{References}

[1] S. Mondal, Y. Hangun-Balkir, L. Alexandrova, D. Link, B. Howard, P. Zandhuis, A. Cugini, C.P. Horwitz, T.J. Collins, Oxidation of sulfur components in diesel fuel using Fe-TAML ${ }^{\circledR}$ catalysts and hydrogen peroxide, Catalysis Today, 116 (2006) 554-561.

[2] Z.E.A. Abdalla, B. Li, Preparation of MCM-41 supported (Bu4N)4H3(PW11O39) catalyst and its performance in oxidative desulfurization, Chemical Engineering Journal, 200 (2012) 113121.

[3] M. Zhang, W. Zhu, S. Xun, H. Li, Q. Gu, Z. Zhao, Q. Wang, Deep oxidative desulfurization of dibenzothiophene with POM-based hybrid materials in ionic liquids, Chemical Engineering Journal, 220 (2013) 328-336.

[4] Y. Zhang, H. Lü, L. Wang, Y. Zhang, P. Liu, H. Han, Z. Jiang, C. Li, The oxidation of benzothiophene using the Keggin-type lacunary polytungstophosphate as catalysts in emulsion, Journal of Molecular Catalysis A: Chemical, 332 (2010) 59-64.

[5] R. Wang, G. Zhang, H. Zhao, Polyoxometalate as effective catalyst for the deep desulfurization of diesel oil, Catalysis Today, 149 (2010) 117-121.

[6] G.S. Armatas, Chapter 13 - Heterogeneous Polyoxometalate-Containing Mesoporous Catalysts A2 - Suib, Steven L, in: New and Future Developments in Catalysis, Elsevier, Amsterdam, 2013, pp. 311-342.

[7] B.J.S. Johnson, A. Stein, Surface Modification of Mesoporous, Macroporous, and Amorphous Silica with Catalytically Active Polyoxometalate Clusters, Inorganic Chemistry, 40 (2001) 801-808.

[8] S.-S. Wang, G.-Y. Yang, Recent Advances in Polyoxometalate-Catalyzed Reactions, Chemical Reviews, 115 (2015) 4893-4962.

[9] J. Diana, R. Susana, C. Baltazar de, C.-S. Luís, S.B. Salete, Polyoxometalates-Based Nanocatalysts for Production of Sulfur-Free Diesel, in: A.S. Tawfik (Ed.) Applying Nanotechnology to the Desulfurization Process in Petroleum Engineering, IGI Global, Hershey, PA, USA, 2016, pp. 426-458.

[10] S. Ribeiro, A.D.S. Barbosa, A.C. Gomes, M. Pillinger, I.S. Gonçalves, L. Cunha-Silva, S.S. Balula, Catalytic oxidative desulfurization systems based on Keggin phosphotungstate and metal-organic framework MIL-101, Fuel Processing Technology, 116 (2013) 350-357.

[11] C.M. Granadeiro, A.D.S. Barbosa, P. Silva, F.A.A. Paz, V.K. Saini, J. Pires, B. de Castro, S.S. Balula, L. Cunha-Silva, Monovacant polyoxometalates incorporated into MIL-101(Cr): novel heterogeneous catalysts for liquid phase oxidation, Applied Catalysis A: General, 453 (2013) 316-326.

[12] D. Julião, A.C. Gomes, M. Pillinger, L. Cunha-Silva, B. de Castro, I.S. Gonçalves, S.S. Balula, Desulfurization of model diesel by extraction/oxidation using a zinc-substituted polyoxometalate as catalyst under homogeneous and heterogeneous (MIL-101(Cr) encapsulated) conditions, Fuel Processing Technology, 131 (2015) 78-86.

[13] L.S. Nogueira, S. Ribeiro, C.M. Granadeiro, E. Pereira, G. Feio, L. Cunha-Silva, S.S. Balula, Novel polyoxometalate silica nano-sized spheres: efficient catalysts for olefin oxidation and the deep desulfurization process, Dalton Trans, 43 (2014) 9518-9528.

[14] M. Li, M. Zhang, A. Wei, W. Zhu, S. Xun, Y. Li, H. Li, H. Li, Facile synthesis of amphiphilic polyoxometalate-based ionic liquid supported silica induced efficient performance in oxidative desulfurization, Journal of Molecular Catalysis A: Chemical, 406 (2015) 23-30.

[15] H.-X. Qi, S.-R. Zhai, W. Zhang, B. Zhai, Q.-D. An, Recyclable HPW/PEHA/ZrSBA-15 toward efficient oxidative desulfurization of DBT with hydrogen peroxide, Catalysis Communications, 72 (2015) 53-56.

[16] Z.E.A. Abdalla, B. Li, Preparation of MCM-41 supported (Bu4N)4H3(PW11O39) catalyst and its performance in oxidative desulfurization, Chemical Engineering Journal, 200 (2012) 113121. 
[17] Z.E.A. Abdalla, B. Li, A. Tufail, Direct synthesis of mesoporous

(C19H42N)4H3(PW11O39)/SiO2 and its catalytic performance in oxidative desulfurization,

Colloids and Surfaces A: Physicochemical and Engineering Aspects, 341 (2009) 86-92.

[18] N. Wu, B. Li, Z. Liu, C. Han, Synthesis of Keggin-type lacunary 11-tungstophosphates encapsulated into mesoporous silica pillared in clay interlayer galleries and their catalytic performance in oxidative desulfurization, Catalysis Communications, 46 (2014) 156-160. [19] S.O. Ribeiro, D. Juliao, L. Cunha-Silva, V.F. Domingues, R. Valenca, J.C. Ribeiro, B. de Castro, S.S. Balula, Catalytic oxidative/extractive desulfurization of model and untreated diesel using hybrid based zinc-substituted polyoxometalates, Fuel, 166 (2016) 268-275.

[20] F. Mirante, L. Dias, M. Silva, S.O. Ribeiro, M.C. Corvo, B. de Castro, C.M. Granadeiro, S.S. Balula, Efficient heterogeneous polyoxometalate-hybrid catalysts for the oxidative desulfurization of fuels, Catalysis Communications, 104 (2018) 1-8.

[21] C. Pereira, K. Biernacki, S.L.H. Rebelo, A.L. Magalhães, A.P. Carvalho, J. Pires, C. Freire, Designing heterogeneous oxovanadium and copper acetylacetonate catalysts: Effect of covalent immobilisation in epoxidation and aziridination reactions, Journal of Molecular Catalysis A: Chemical, 312 (2009) 53-64.

[22] S.S. Balula, I.C.M.S. Santos, L. Cunha-Silva, A.P. Carvalho, J. Pires, C. Freire, J.A.S. Cavaleiro, B. de Castro, A.M.V. Cavaleiro, Phosphotungstates as catalysts for monoterpenes oxidation: Homo- and heterogeneous performance, Catalysis Today, 203 (2013) 95-102.

[23] F. Mirante, S.O. Ribeiro, B. de Castro, C.M. Granadeiro, S.S. Balula, Sustainable Desulfurization Processes Catalyzed by Titanium-Polyoxometalate@TM-SBA-15, Topics in Catalysis, (2017) 1-11.

[24] S.O. Ribeiro, L.S. Nogueira, S. Gago, P.L. Almeida, M.C. Corvo, B.d. Castro, C.M. Granadeiro, S.S. Balula, Desulfurization process conciliating heterogeneous oxidation and liquid extraction: Organic solvent or centrifugation/water?, Applied Catalysis A: General, 542 (2017) 359-367.

[25] X. Wang, K.S.K. Lin, J.C.C. Chan, S. Cheng, Preparation of ordered large pore SBA-15 silica functionalized with aminopropyl groups through one-pot synthesis, Chemical Communications, (2004) 2762-2763.

[26] Y. Zhou, R. Bao, B. Yue, M. Gu, S. Pei, H. He, Synthesis, characterization and catalytic application of SBA-15 immobilized rare earth metal sandwiched polyoxometalates, Journal of Molecular Catalysis A: Chemical, 270 (2007) 50-55.

[27] D. Julião, R. Valença, J.C. Ribeiro, B. de Castro, S.S. Balula, Efficient eco-sustainable ionic liquid-polyoxometalate desulfurization processes for model and real diesel, Applied Catalysis A: General, 537 (2017) 93-99.

[28] M.M.Q. Simões, C.M.M. Conceição, J.A.F. Gamelas, P.M.D.N. Domingues, A.M.V. Cavaleiro, J.A.S. Cavaleiro, A.J.V. Ferrer-Correia, R.A.W. Johnstone, Keggin-type polyoxotungstates as catalysts in the oxidation of cyclohexane by dilute aqueous hydrogen peroxide, Journal of Molecular Catalysis A: Chemical, 144 (1999) 461-468.

[29] S.S. Balula, L. Cunha-Silva, I.C.M.S. Santos, A.C. Estrada, A.C. Fernandes, J.A.S. Cavaleiro, J. Pires, C. Freire, A.M.V. Cavaleiro, Mono-substituted silicotungstates as active catalysts for sustainable oxidations: homo- and heterogeneous performance, New Journal of Chemistry, 37 (2013) 2341-2350.

[30] R.C. Schroden, C.F. Blanford, B.J. Melde, B.J.S. Johnson, A. Stein, Direct Synthesis of Ordered Macroporous Silica Materials Functionalized with Polyoxometalate Clusters, Chemistry of Materials, 13 (2001) 1074-1081.

[31] X. Wang, P. Wang, Z. Dong, Z. Dong, Z. Ma, J. Jiang, R. Li, J. Ma, Highly Sensitive Fluorescence Probe Based on Functional SBA-15 for Selective Detection of $\mathrm{Hg}(2+)$, Nanoscale Research Letters, 5 (2010) 1468-1473.

[32] C. Rocchiccioli-Deltcheff, M. Fournier, R. Franck, R. Thouvenot, Vibrational investigations of polyoxometalates. 2. Evidence for anion-anion interactions in molybdenum(VI) and 
tungsten(VI) compounds related to the Keggin structure, Inorganic Chemistry, 22 (1983) 207216.

[33] J.L.C. Sousa, I.C.M.S. Santos, M.M.Q. Simões, J.A.S. Cavaleiro, H.I.S. Nogueira, A.M.V. Cavaleiro, Iron(III)-substituted polyoxotungstates immobilized on silica nanoparticles: Novel oxidative heterogeneous catalysts, Catalysis Communications, 12 (2011) 459-463.

[34] A. Bordoloi, F. Lefebvre, S.B. Halligudi, Selective oxidation of anthracene using inorganicorganic hybrid materials based on molybdovanadophosphoric acids, Journal of Catalysis, 247 (2007) 166-175.

[35] D. Mauder, D. Akcakayiran, S.B. Lesnichin, G.H. Findenegg, I.G. Shenderovich, Acidity of Sulfonic and Phosphonic Acid-Functionalized SBA-15 under Almost Water-Free Conditions, The Journal of Physical Chemistry C, 113 (2009) 19185-19192.

[36] R. Zhang, C. Yang, A novel polyoxometalate-functionalized mesoporous hybrid silica: synthesis and characterization, Journal of Materials Chemistry, 18 (2008) 2691-2703.

[37] A. Bordoloi, N.T. Mathew, F. Lefebvre, S.B. Halligudi, Inorganic-organic hybrid materials based on functionalized silica and carbon: A comprehensive understanding toward the structural property and catalytic activity difference over mesoporous silica and carbon supports, Microporous and Mesoporous Materials, 115 (2008) 345-355.

[38] A.S. Maria Chong, X.S. Zhao, Functionalization of SBA-15 with APTES and Characterization of Functionalized Materials, The Journal of Physical Chemistry B, 107 (2003) 12650-12657.

[39] X. Wang, K.S.K. Lin, J.C.C. Chan, S. Cheng, Direct Synthesis and Catalytic Applications of Ordered Large Pore Aminopropyl-Functionalized SBA-15 Mesoporous Materials, The Journal of Physical Chemistry B, 109 (2005) 1763-1769.

[40] G.S. Caravajal, D.E. Leyden, G.R. Quinting, G.E. Maciel, Structural characterization of (3aminopropyl)triethoxysilane-modified silicas by silicon-29 and carbon-13 nuclear magnetic resonance, Analytical Chemistry, 60 (1988) 1776-1786.

[41] Z. Luan, J.A. Fournier, J.B. Wooten, D.E. Miser, Preparation and characterization of (3aminopropyl)triethoxysilane-modified mesoporous SBA-15 silica molecular sieves,

Microporous and Mesoporous Materials, 83 (2005) 150-158.

[42] M. Kruk, M. Jaroniec, C.H. Ko, R. Ryoo, Characterization of the Porous Structure of SBA-15, Chemistry of Materials, 12 (2000) 1961-1968.

[43] D. Zhao, J. Feng, Q. Huo, N. Melosh, G.H. Fredrickson, B.F. Chmelka, G.D. Stucky, Triblock Copolymer Syntheses of Mesoporous Silica with Periodic 50 to 300 Angstrom Pores, Science, 279 (1998) 548-552.

[44] M. Thommes, K. Kaneko, V. Neimark Alexander, P. Olivier James, F. Rodriguez-Reinoso, J. Rouquerol, S.W. Sing Kenneth, Physisorption of gases, with special reference to the evaluation of surface area and pore size distribution (IUPAC Technical Report), in: Pure and Applied Chemistry, 2015, pp. 1051.

[45] A. Lapkin, B. Bozkaya, T. Mays, L. Borello, K. Edler, B. Crittenden, Preparation and characterisation of chemisorbents based on heteropolyacids supported on synthetic mesoporous carbons and silica, Catalysis Today, 81 (2003) 611-621.

[46] L.S. Nogueira, S. Ribeiro, C.M. Granadeiro, E. Pereira, G. Feio, L. Cunha-Silva, S.S. Balula, Novel polyoxometalate silica nano-sized spheres: efficient catalysts for olefin oxidation and the deep desulfurization process, Dalton Transactions, 43 (2014) 9518-9528.

[47] J. Gao, Y. Chen, B. Han, Z. Feng, C. Li, N. Zhou, S. Gao, Z. Xi, A spectroscopic study on the reaction-controlled phase transfer catalyst in the epoxidation of cyclohexene, Journal of Molecular Catalysis A: Chemical, 210 (2004) 197-204.

[48] Z. Weng, J. Wang, X. Jian, A reusable and active lacunary derivative [PW11039]7- as benzyl alcohol oxidation catalyst with hydrogen peroxide, Catalysis Communications, 9 (2008) 1688-1691.

[49] F. Mirante, L. Dias, M. Silva, S.O. Ribeiro, M.C. Corvo, B. de Castro, C.M. Granadeiro, S.S. Balula, Efficient heterogeneous polyoxometalate-hybrid catalysts for the oxidative desulfurization of fuels, Catalysis Communications, 104 (2018) 1-8. 
[50] L. Liu, C. Chen, X. Hu, T. Mohamood, W. Ma, J. Lin, J. Zhao, A role of ionic liquid as an activator for efficient olefin epoxidation catalyzed by polyoxometalate, New Journal of Chemistry, 32 (2008) 283-289.

[51] C. Aubry, G. Chottard, N. Platzer, J.M. Bregeault, R. Thouvenot, F. Chauveau, C. Huet, H. Ledon, Reinvestigation of epoxidation using tungsten-based precursors and hydrogen peroxide in a biphase medium, Inorganic Chemistry, 30 (1991) 4409-4415.

[52] Y. Liu, K. Murata, T. Hanaoka, M. Inaba, K. Sakanishi, Syntheses of new peroxopolyoxometalates intercalated layered double hydroxides for propene epoxidation by molecular oxygen in methanol, Journal of Catalysis, 248 (2007) 277-287. 